\title{
Coupled glass and structure response of conventional curtain walls subjected to blast loads: validation tests and analysis
}

\author{
Kirk Marchand · Carrie Davis $($ Eric Sammarco • \\ Joeny Bui · Jim Casper
}

Received: 26 December 2015 / Accepted: 28 September 2016 / Published online: 14 December 2016

(C) Springer International Publishing Switzerland 2016

\begin{abstract}
This paper presents comparisons of analysis predictions and shock tube test results from a recent dynamic test program involving a conventional Enclos curtain wall system designed solely for wind and gravity loads. Measured blast wave induced glazing response and mullion deflections are compared to response predictions made using fast running nonlinear finite element analysis (FEA) techniques incorporating LS-DYNA based finite element analysis of structural mullions and FEA implementation of statistical glass fracture prediction techniques. The design-level nonlinear finite element analysis was performed using WhAM [window (hazard) analysis module], a fastrunning, web-based design tool for blast-loaded curtain wall systems. WhAM was developed by Protection Engineering Consultants (PEC) with support from the Enclos Advanced Technology Studio. Post-test comparisons between measured and predicted system and component-level response were carried out to (a) evaluate the accuracy of WhAM, and (b) illustrate how the precision test data can be used to enhance certain features of the WhAM software such as its glass material model (an LS-DYNA user-defined constitutive model
\end{abstract}

C. Davis $(\varangle) \cdot$ E. Sammarco · J. Bui

Protection Engineering Consultants, Austin, TX, USA

e-mail: cdavis@protection-consultants.com

K. Marchand

Protection Engineering Consultants, San Antonio, TX, USA

J. Casper

Enclos Advanced Technology Studio, Eagan, MN, USA with probabilistic failure criterion based on the ASTM E1300 glass failure prediction model and dynamic test data) and simplified modeling techniques for connection details. Note that SI units are used throughout the text of this paper. American/imperial units are also provided in tables when raw data was originally recorded in those units. Data plots resulting from raw data are also presented in American/imperial units.

Keywords Curtain wall $\cdot$ Blast loads . Finite element analysis $\cdot$ Testing $\cdot$ Modeling

\section{Introduction}

Failure of blast-loaded building facades and window systems cause many of the injuries reported after bombing events and accidental explosions such as the 1995 Oklahoma City Bombing, the 2011 Oslo Regjeringskvartalet Bombing, and the 2015 Mexico City Hospital gas explosion. As building facades continue to incorporate larger areas of advanced glazing elements, the probability of human injuries or fatalities from glazing debris increases. Therefore, design requirements for accidental and deliberate attack are becoming more prevalent for window and curtain wall systems.

Protection Engineering Consultants (PEC) partnered with Enclos Studio to develop the Window (hazard) Analysis Module (WhAM), a fast-running design and analysis tool for curtain walls subjected to blast loads. An initial phase of this effort included five full- 
scale shock tube tests. These tests were performed as part of the proof-of-capabilities study in the WhAM development. Enclos provided eight identical window assemblies including glazing, mullions, and connectors. This paper summarizes the test modules, test setup, instrumentation, test results, and analysis results. Post-test comparisons between measured and predicted deflections were performed to evaluate the accuracy of the current version of WhAM and illustrate how the data will be used to update the WhAM glass model and glass/frame interaction. Additional post-test analyses evaluated the overall system response with rigid anchors and compared measured loads imposed at each anchor point on the structural supports (i.e., shock tube) to predicted reactions.

This work builds upon previous work conducted for the Air Force Research Laboratory (AFRL) and PPG Industries (Davis et al. 2009; Alberson et al. 2013) to validate a model capable of predicting glass failure for both static and dynamic loads through shock tube testing and full scale blast testing of single windows and storefront systems. The Glass Failure Prediction Model (GFPM) developed by Beason and Morgan (1984) was chosen for its incorporation of load rate, empirical flaw probability distribution (validated), and because it is the basis for the industry standard ASTM E1300 design methodology (ASTM 2012).

The GFPM uses a finite difference model after Vallabhan and Wang (1981) to correlate the lateral pressure on a given piece of glass to its stress distribution. The stress is then modified to account for load duration and biaxiality, which is referenced as the equivalent stress. The equivalent stress is incorporated into a Weibull distribution where empirical flaw parameters $(\mathrm{m}, \mathrm{k})$ define the shape of the Weibull distribution and relate equivalent stress to the probability of failure.

SBEDS-W (Single degree of freedom Blast Effects Design Spreadsheet for Windows) (USACE 2012) uses the GFPM to predict glass failure for SDOF analysis. Specifically, SBEDS-W uses the method presented in ASTM E1300 Appendix X3. Use of the stress distribution factor, J, eliminates the need to explicitly map the relationship between lateral load and stress in the glass. However, the stress distribution factor is based on testing of AN glass only. To accommodate the increased strength of heat strengthened and tempered glass, a strength multiplier was added to the model which has a similar effect as altering the $\mathrm{k}$ parameter of the Weibull distribution found in the GFPM. Due to this modification, the $\mathrm{k}$ parameter is fixed at a value of $2.86 \times 10^{-53}$ $\mathrm{N}^{-7} \mathrm{~m}^{12}$ in SBEDS-W. Therefore, the $\mathrm{m}$ parameter is the only variable used to calibrate differing strengths of glass (in addition to the embedded strength factor). This parameter was established through both static and dynamic testing.

WhAM is further described in Sect. 3 below. This paper describes work accomplished in the validation of selected features of the tool. Enhancements described in Sect. 3 will be validated at a later date. In addition, other research on the characterization of glass and curtain wall simulations subjected to blast loads will be reviewed and explored to further improve WhAM as a fast running design tool (Bedon and Amadio 2014; Deng and Jin 2010; Hidallana-Gamage et al. 2014; Larcher et al. 2012; Pelfrene et al. 2016; Zhang et al. 2013).

\section{Window design tools}

Current design approaches typically use single degree of freedom (SDOF) methods to analyze the performance of window glazing and mullions. The flexural resistance and mass of each component must be identified to define the SDOF representation. Then, the resistance curve is calculated based on span, support conditions, cross sectional stiffness, assumed deformed shape, and a failure criterion. SDOF methods have significant limitations when used for analysis of complex glazing systems such as storefronts and curtain walls. Coupling effects are ignored in SDOF methods, and only single assumed modes of response can be considered. The use of finite element analysis (FEA) techniques can eliminate the assumptions made regarding mass distribution and deformed shape and facilitates spatial fracture prediction at appropriate points on the glass surface. FEA can also ultimately remove SDOF analysis restrictions including rectilinear and flat glass.

The chief objective of WhAM is to function as a fast-running and accurate design-level tool for façade and curtain wall systems. As such, development of a finite element model for the curtain wall specimen encompassed the same design-level fidelity as would be employed with WhAM. For the work reported here, FEA models were developed and used an inferred engineering failure stress from SDOF models (SBEDS-W) that included a GFPM implementation and where 
Table 1 Test matrix

\begin{tabular}{lllll}
\hline Test no. & Modules & \multicolumn{2}{l}{ Measured blast load } & Test results \\
\cline { 3 - 4 } & & $\begin{array}{l}\text { Pressure } \\
\text { (kpa, psi) }\end{array}$ & $\begin{array}{l}\text { Impulse } \\
\text { (kpa-ms, psi-ms) }\end{array}$ & \\
\hline 1 & 1 and 2 & $30.3,4.4$ & $151.7,22$ & Elastic response of system \\
2 & 1 and 2 (re-used due to & $53.1,7.7$ & $262.0,38$ & Begin to fail lower and upper glass \\
3 & limited damage in Test 1) & & & Push upper glass to failure, begin to fail lower glass \\
4 & 3 and 4 & $76.5,11.1$ & $406.8,59$ & Exercise coupled glass and mullion response \\
5 & 5 and 6 & $93.8,13.6$ & $530.9,77$ & Push system to maximum response \\
\hline
\end{tabular}

deformed shape was matched to FEA models. This inferred stress was then used as a fracture stress for fully dynamic FEA analysis without a-priori deformed shape definition.

Current but as-of-yet not validated computational features of WhAM include advanced user-defined constitutive models (UMATs) that have been vectorized and implemented in SMP and MPP parallel processing structures within a computational model programmatically incorporating the multi-physics finite element code LS-DYNA (LSTC 2015). Key numerical formulations include the GFPM based LS-DYNA UMAT with an elastic constitutive model with flaw-based probabilistic failure criterion. The PVB interlayer LS-DYNA UMAT includes a post-break, strain-based stiffness increase due to interaction between PVB and adhered glass shards (USACE 2012; Schneider et al. 2012). The structural silicone LS-DYNA UMAT includes a hyperelastic constitutive model that accounts for dynamic strength increase due to both strain and strain rate (MPA Stuttgart 2007).

\section{Shock tube testing}

PEC performed five shock tube tests on eight identical full-scale curtain wall modules (two per test with one pair reused after Test 1) to evaluate the performance of a sample curtain wall system and to provide data for comparison with the FEA. The blast load applied to the curtain walls was varied to achieve a range of responses from "no break" glass response up to glass fracture with significant PVB and mullion response. The curtain wall modules including mullions, insulating glass units (IGUs), and the top connection. The test matrix is shown in Table 1 . Note that modules 1 and 2 were used in both Tests 1 and 2 .

\subsection{Test modules}

All curtain wall modules had a nominal dimension of $1.68 \mathrm{~m}$ wide $\times 3.15 \mathrm{~m}$ tall. A single test specimen consisted of two curtain wall modules and had a nominal width of $3.48 \mathrm{~m}$. Each curtain wall module was composed of two insulating glazing unit (IGU) configurations. The upper IGU had a day light opening of $1.58 \mathrm{~m} \times 0.63 \mathrm{~m}$. The $33.3 \mathrm{~mm}$ nominal heat strengthened (HS) IGU consisted of a $7.9 \mathrm{~mm}$ nominal $(7.4 \mathrm{~mm}$ actual) HS outer lite $\times 19.1 \mathrm{~mm}$ air gap $\times 6.4 \mathrm{~mm}$ nominal $(5.6 \mathrm{~mm}$ actual) HS inner lite. The lower IGU had a day light opening of $1.58 \mathrm{~m} \times 2.15 \mathrm{~m}$. The $34.9 \mathrm{~mm}$ nominal HS IGU consisted of a $7.9 \mathrm{~mm}$ nominal $(7.4 \mathrm{~mm}$ actual) HS outer lite $\times 12.7 \mathrm{~mm}$ air gap $\times 12.8 \mathrm{~mm}$ nominal HS laminated inner lite ( $6.4 \mathrm{~mm}$ nominal $(5.6 \mathrm{~mm}$ actual) $\mathrm{HS} \times 1.5 \mathrm{~mm}$ PVB $\times 6.4 \mathrm{~mm}$ nominal (5.6 mm actual) HS). In general, a $38.1 \mathrm{~mm}$ glass bite was provided on vertical window edges, while a $25.4 \mathrm{~mm}$ glass bite was provided on horizontal edges. Glass was secured to the aluminum frames with an $18.3 \mathrm{~mm}$ (minimum) bead of Dow Corning 983 structural glazing sealant (structural silicone). PVB interlayer was $1.5 \mathrm{~mm}$ nominal (0.060 in actual) Butacite.

All glass provided had been manufactured in accordance with ASTM standards C1036, "Standard Specification for Flat Glass," C1048, "Standard Specification for Heat-Strengthened and Fully Tempered Flat Glass," and C1172, "Standard Specification for Laminated Architectural Flat Glass". Insulated glass units were air filled with desiccant seals.

A $219 \mathrm{~mm}$ deep (178 $\mathrm{mm}$ behind the IGU), 6063-T6 aluminum unit frame was selected to support all units. Mullion cross sections are illustrated in Fig. 1. D1500, 
Table 2 Aluminum mullion properties

\begin{tabular}{|c|c|c|c|c|c|c|}
\hline Section property & $\begin{array}{l}\text { Jamb } 1 \\
\text { D1000 male }\end{array}$ & $\begin{array}{l}\text { Jamb } 2 \\
\text { D1000 female }\end{array}$ & $\begin{array}{l}\text { Vert. mull. }^{\mathrm{a}} \\
\text { D1000 total }\end{array}$ & $\begin{array}{l}\text { Head } \\
\text { D1500 }\end{array}$ & $\begin{array}{l}\text { Horiz. mull. } \\
\text { D1501 }\end{array}$ & $\begin{array}{l}\text { Sill } \\
\text { D1502 }\end{array}$ \\
\hline Area $\left(\mathrm{cm}^{2}\right)$ & 15 & 16 & 31 & 17 & 19 & 18 \\
\hline Depth (mm) & 178 & 178 & 178 & 165 & 219 & 178 \\
\hline Width (mm) & 63 & 44 & 76 & 184 & 80 & 68 \\
\hline Web thickness (mm) & 3.2 & 3.2 & 6.4 & 3.2 & 6.4 & 3.2 \\
\hline \multicolumn{7}{|l|}{ Strong axis } \\
\hline Moment of inertia $\left(\mathrm{cm}^{4}\right)$ & 598 & 594 & 1192 & 236 & 923 & 564 \\
\hline Radius of gyration (mm) & 62 & 61 & 62 & 38 & 69 & 57 \\
\hline Section modulus $\left(\mathrm{cm}^{3}\right)$ & 68 & 64 & 132 & 24 & 92 & 56 \\
\hline Plastic section modulus $\left(\mathrm{cm}^{3}\right)$ & 84 & 83 & 167 & 47 & 119 & 80 \\
\hline \multicolumn{7}{|l|}{ Weak axis } \\
\hline Moment of inertia $\left(\mathrm{cm}^{4}\right)$ & 40 & 26 & 66 & 557 & 202 & 85 \\
\hline Radius of gyration (mm) & 16 & 13 & 14 & 58 & 32 & 22 \\
\hline Section modulus $\left(\mathrm{cm}^{3}\right)$ & 24 & 18 & 42 & 46 & 51 & 20 \\
\hline Plastic section modulus $\left(\mathrm{cm}^{3}\right)$ & 19 & 17 & 37 & 78 & 57 & 34 \\
\hline
\end{tabular}

${ }^{\mathrm{a}}$ Combined non-compositely

D1501, and D1502 were used at all head, horizontal mullion, and sill locations (respectively), while D1000 was used at the intermediate vertical mullion and jambs. D1000 was snapped together in the front and back for on-site installation. In addition, the section was economized by optimizing metal placement (front and back walls were thicker), which increased the section modulus and flexural capacity (see Table 2). For analysis, the D1000 male and female mullion properties were combined assuming non-composite action. Jambs consisted of either the D1000 male or female mullion to more closely approximate the response of another vertical mullion with only half of the applied load. The top $305 \mathrm{~mm}$ of each jamb a steel closure plate was provided to prevent eccentricity into the top anchor connections.

\subsection{Test set-up and instrumentation}

The shock tube opening (about $3.66 \mathrm{~m} \times 4.88 \mathrm{~m}$ ) was modified to accommodate the test modules. Steel side plates and wood shims were added to ensure minimal gaps on each side (less than $3.2 \mathrm{~mm}$ ). A steel closure plate was added to infill the opening at the top of the shock tube. The shock tube opening is illustrated in Fig. 2. Each vertical mullion and jamb was supported at top and bottom (spanning vertically) by the shock tube structural steel at the opening.
An HSS steel tube was provided behind the top connection to accommodate the standard anchoring system at three locations. The standard top anchors approximated typical construction details as closely as possible, as shown in Fig. 3. The bottom connections were made with custom steel inserts to directly transfer bearing and shear similar to the typical stack joint, as shown in Fig. 4. The connections were designed for the maximum reaction (based on ultimate capacity of the members) of $101 \mathrm{kN}$ at the end of the vertical mullion and $50 \mathrm{kN}$ at the end of each jamb (note, some connection failures were observed during Test 4 and 5).

Instrumentation during each shock tube test included pressure gauges, laser deflection gauges, digital image correlation equipment, load cells, temperature gauges, string potentiometers, and high-speed video cameras (see Fig. 5). Still photographs documented the modules before and after each test. The following sections outline the quantity, location, and type of instrumentation used during each test.

Four pressure transducers were installed on the shock tube walls (flush with interior wall) to determine the applied loads (peak reflected pressure, load duration, and peak reflected impulse), as shown in Fig. 5. The pressure gauge measurements were averaged after each test to determine an applied load. The pressure gauges were located in the corner where the shock tube 
Fig. 1 Mullion cross sections

Fig. 2 Shock tube opening with window assembly in place
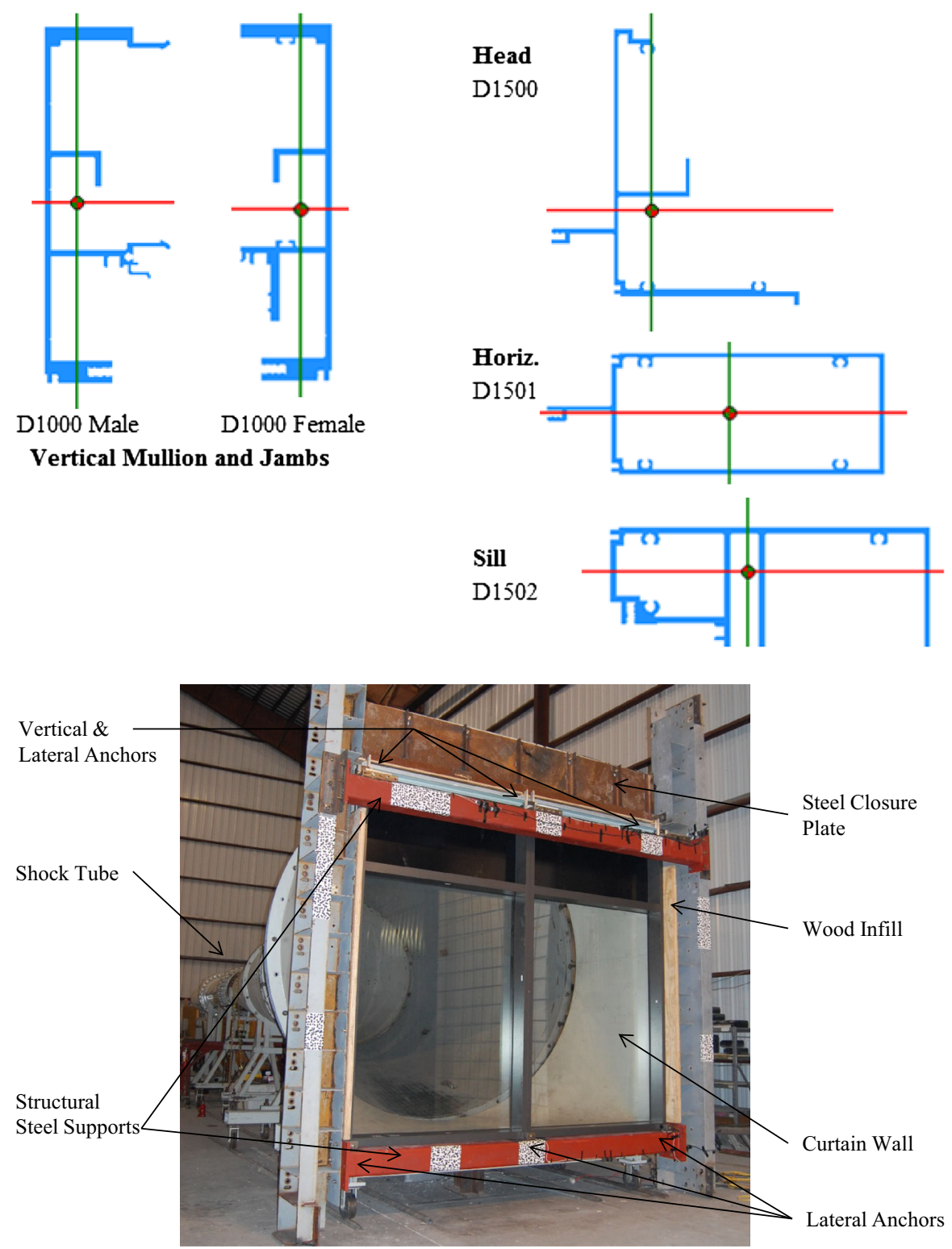

wall and front face meet to best approximate the load on the specimen. Pre-test shots were performed to verify the accuracy and consistency of pressure gauges mounted in the shock tube wall. During the calibration testing, measured impulses varied less than $5 \%$, while peak pressures varied up to $20 \%$. During testing, the measured impulse varied less than $3 \%$, while the pressure variation improved to $10 \%$.

Digital image correlation (DIC) was employed to record displacement measurements of the glazing and frame system. The DIC setup used paired Vision
Research V711 high-speed cameras so as to record stereoscopically. Each camera was outfitted with a Zeiss ZE 35mm f/1.4 lens (f3.3 used during testing) and operated at 7500 frames per second with a $1280 \times 800$ resolution. Based on the field of view and exposure time of $5 \mu \mathrm{s}$, the worst case out-of-plane motion blur was estimated to be $0.0077 \mathrm{pixel} / \mathrm{exposure}$ which is well below the $0.01 \mathrm{pixel} / \mathrm{exposure}$ recommendation by DIC. The cameras were mounted and enclosed in custom built protective aluminum boxes with $12.7 \mathrm{~mm}$ thick Lexan viewports. The cameras were mounted to a 
Fig. 3 Top connections ("LC" refers to load cell)

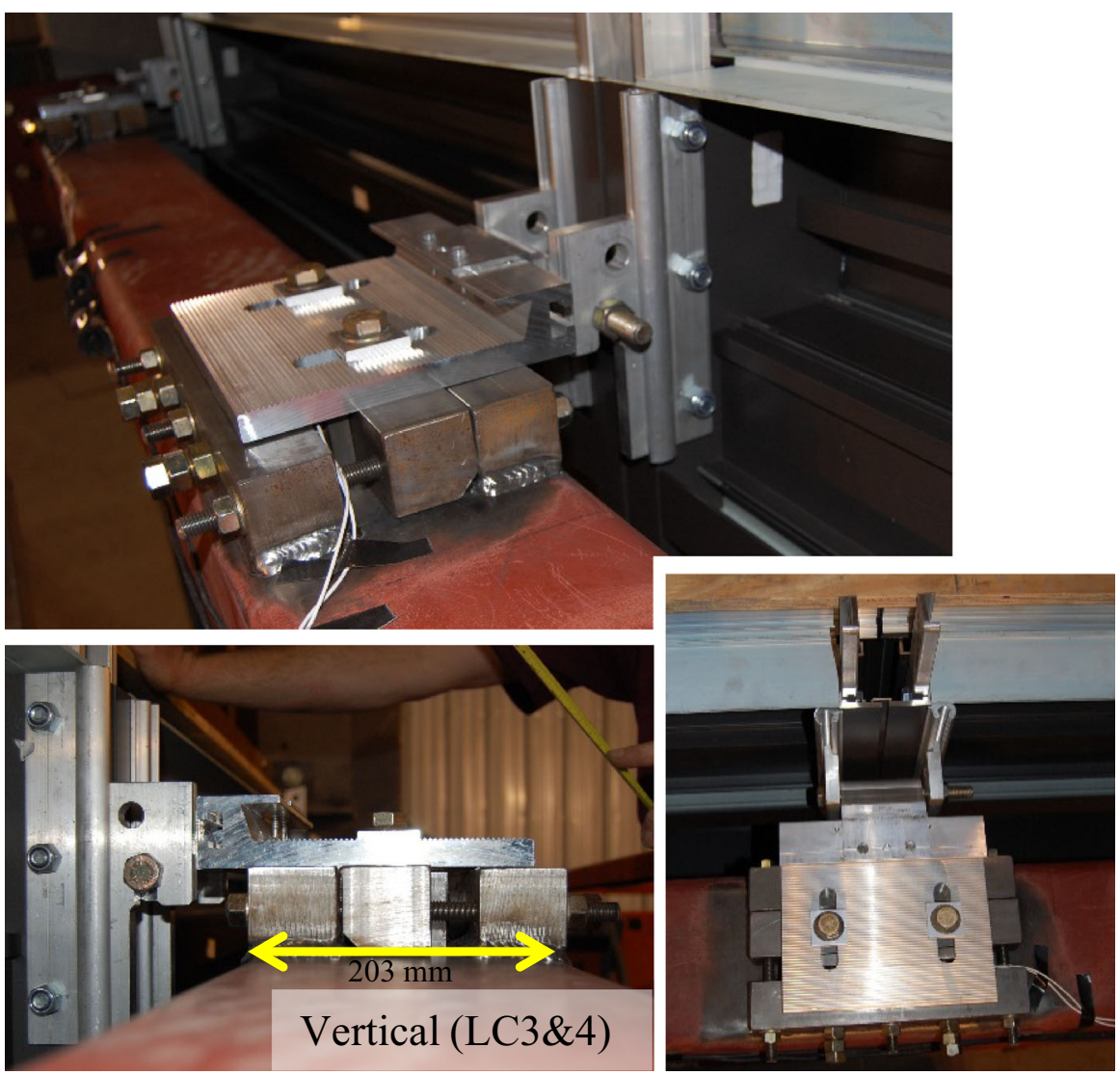

Fig. 4 Bottom connections ("LC" refers to load cell)
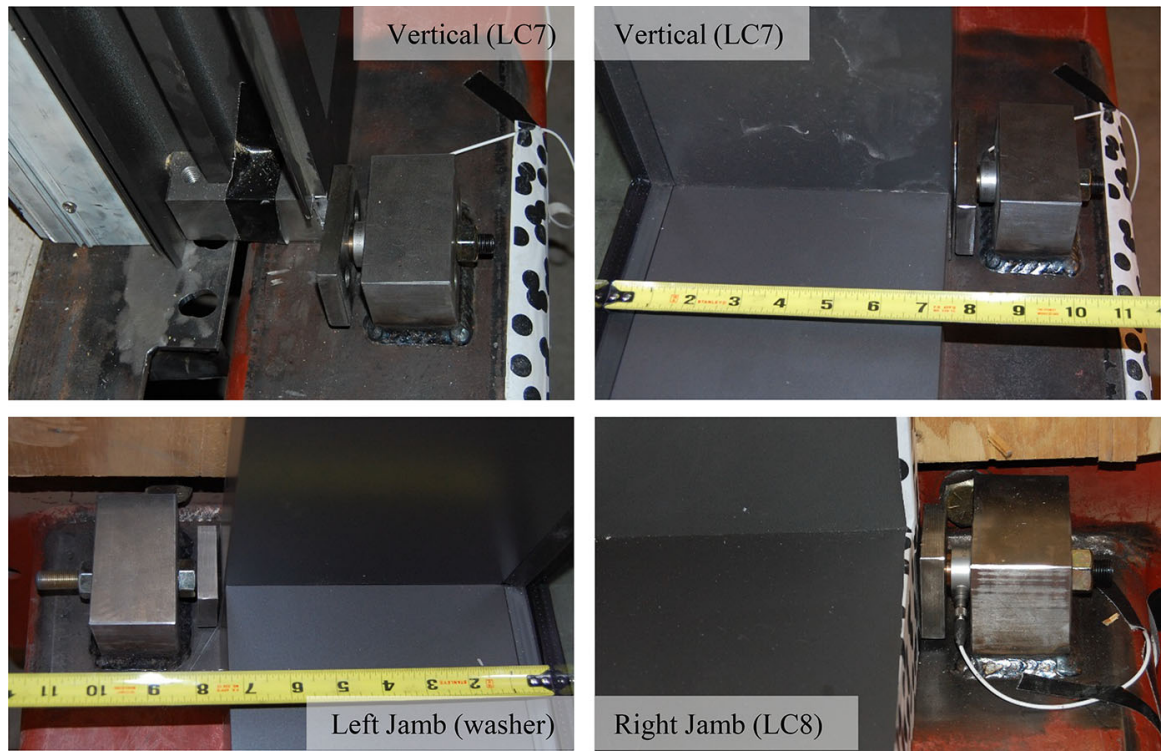

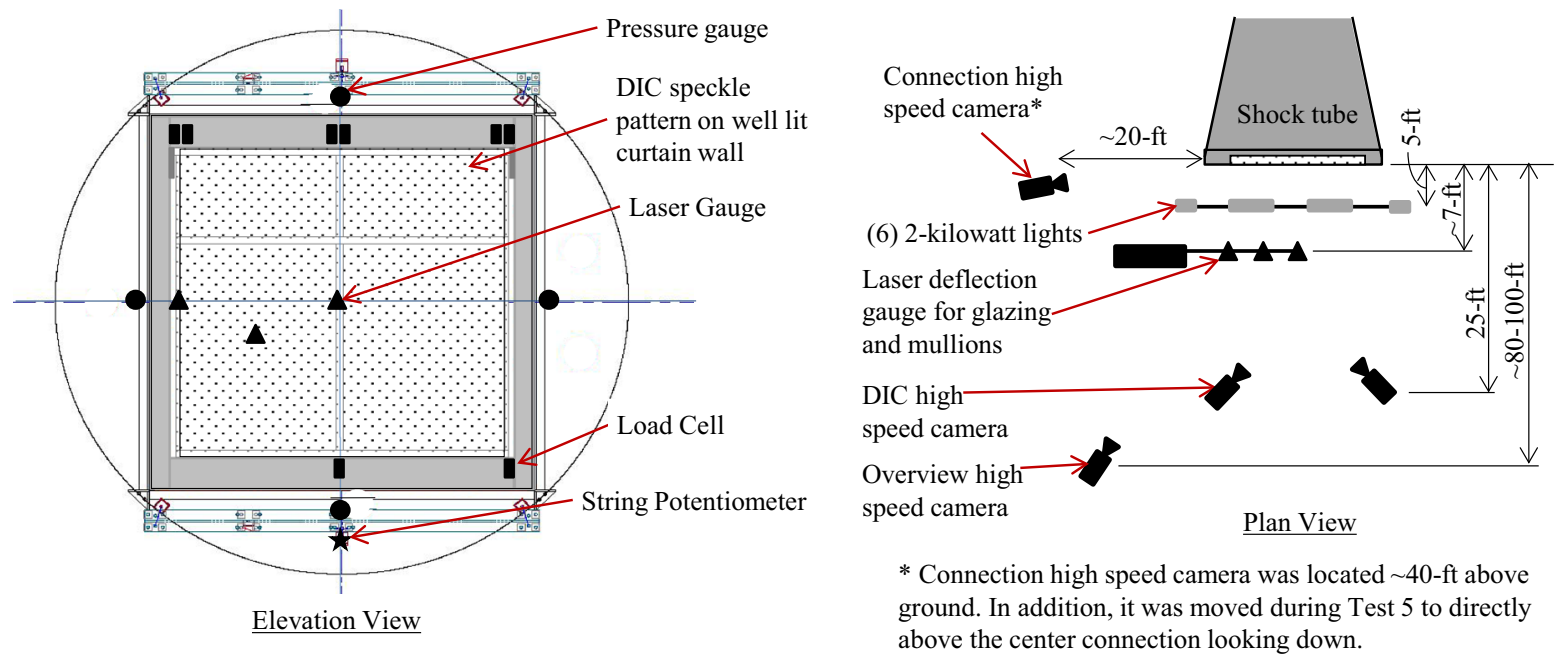

Fig. 5 Typical instrumentation layout (laser gauges moved to 1/3rd points in Tests 4 and 5)

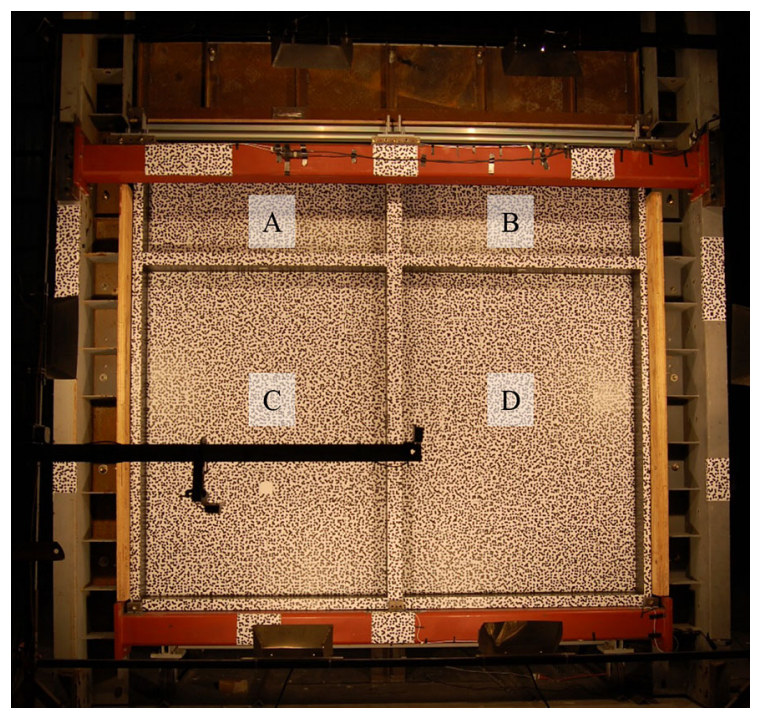

Fig. 6 DIC speckle pattern

$203 \mathrm{~mm}$ HSS crossbeam on the camera tree; which was in turn mounted to the concrete floor with four epoxy set $12.7 \mathrm{~mm}$ Hilti Anchors.

A high contrast (black and white) speckle pattern was applied to the entire façade (all glazing and mullions) on the protected side (facing outside of shock tube), as shown in Fig. 6. The pattern was printed on $216 \mathrm{~mm} \times 279 \mathrm{~mm}$ full sheet white packing label paper. The speckle dot diameter was printed at $14.3 \mathrm{~mm}$ (3.2 pixels) which satisfies the 3-4 pixels-to-diameter ratio recommendation by DIC. The paper has high adhesion, minimal shear strength, and was applied with minimal overlap (i.e., some gaps) to insure no membrane action. 2-kilowatt lighting was used for illumination during the tests. Glass and speckle paper temperature was measured with a non-contact temperature gage before and after each test. Temperature increases due to lighting were modest (no greater than 2-degrees $\mathrm{C}$ increase). Previous glass fracture research has shown that the speckle paper has little influence on fracture initiation or strength (Alberson et al. 2013).

The raw DIC data retrieved from the cameras included null data in the dataset, which corresponded to coordinates at each time where the cameras were unable to track the speckle pattern due to blockage from other instrumentation or significant tearing of the speckle pattern paper (i.e., laser gauge instrumentation support, when the upper lites failed and flew out or the vertical mullion split open). The presence of null data required the data to be post-processed into a 2-D linear Delaunay interpolation field. The field was smoothed over empty spots along the 2-D space by interpolating across both axes using Delaunay triangles. Linear interpolation at each point through time was also required because the null data varied with time as the specimen moved and changed positions. The raw DIC data was normalized to account for the shock tube movement. The shock tube movement was measured with a string potentiometer at the bottom of the shock tube. At each time step, all measured DIC data required a uniform shift in displacement with respect to a 1-D interpolation function that matched the string potentiometer data. 
Fig. 7 Laser gage
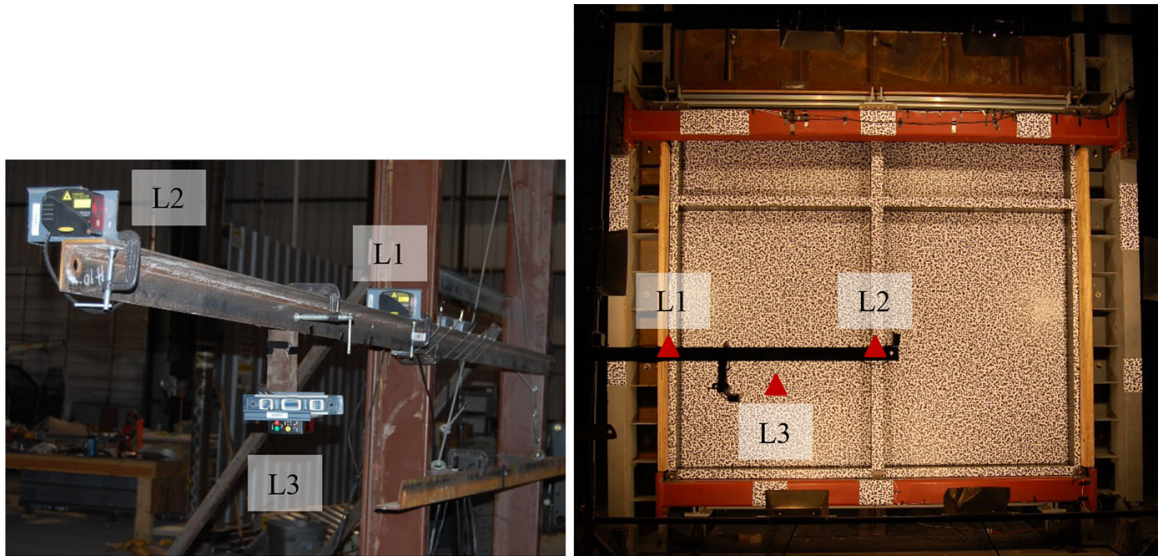

Fig. 8 Load cells
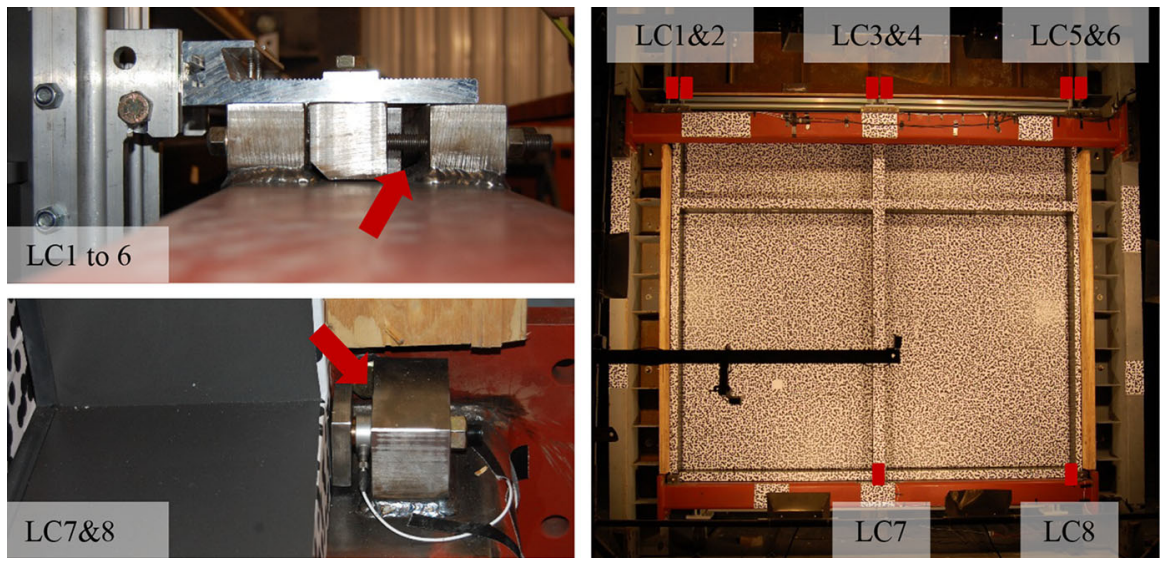
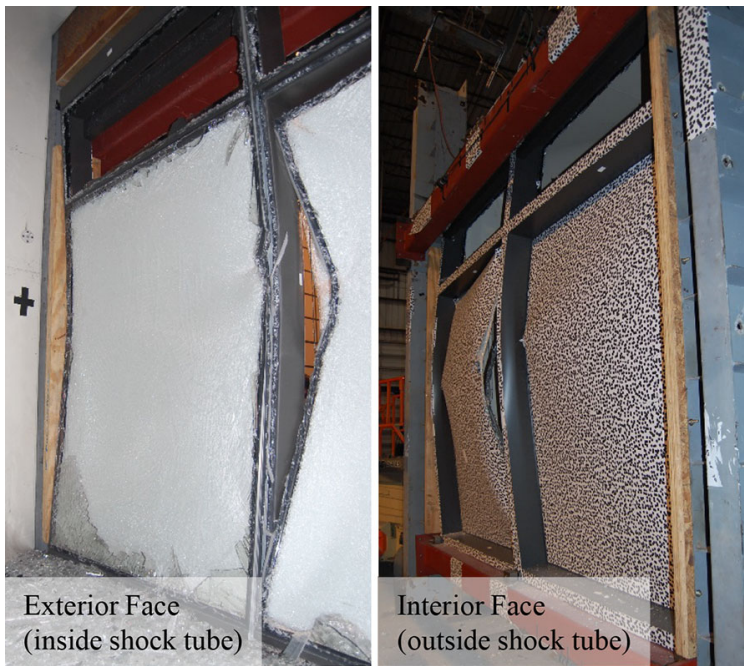

Fig. 9 Typical curtain wall response observed in tests

Three time-of-flight (TOF) laser sensors (see Fig. 7; laser sensors shown as L1, L2, and L3) were used dur- ing each test as a secondary measurement of the maximum glazing and vertical mullion displacements. Two of the lasers where used to monitor the displacement of the left vertical mullion (jamb) and center vertical mullion, and the third laser was used to monitor the displacement of the lower left IGU.

Eight load cells (see Fig. 8) were available to be used during each test to record the member end reaction transferred to each support. Two load cells were used at each top support, while one load cell was used at two of the three bottom supports. A dummy washer having the same thickness as the load cells was used on the left jamb bottom support.

\subsection{Test results}

Typical results from the shock tube tests on curtain wall assemblies are illustrated in Fig. 9. Results were used to evaluate the overall system performance of the glazing and mullions. 


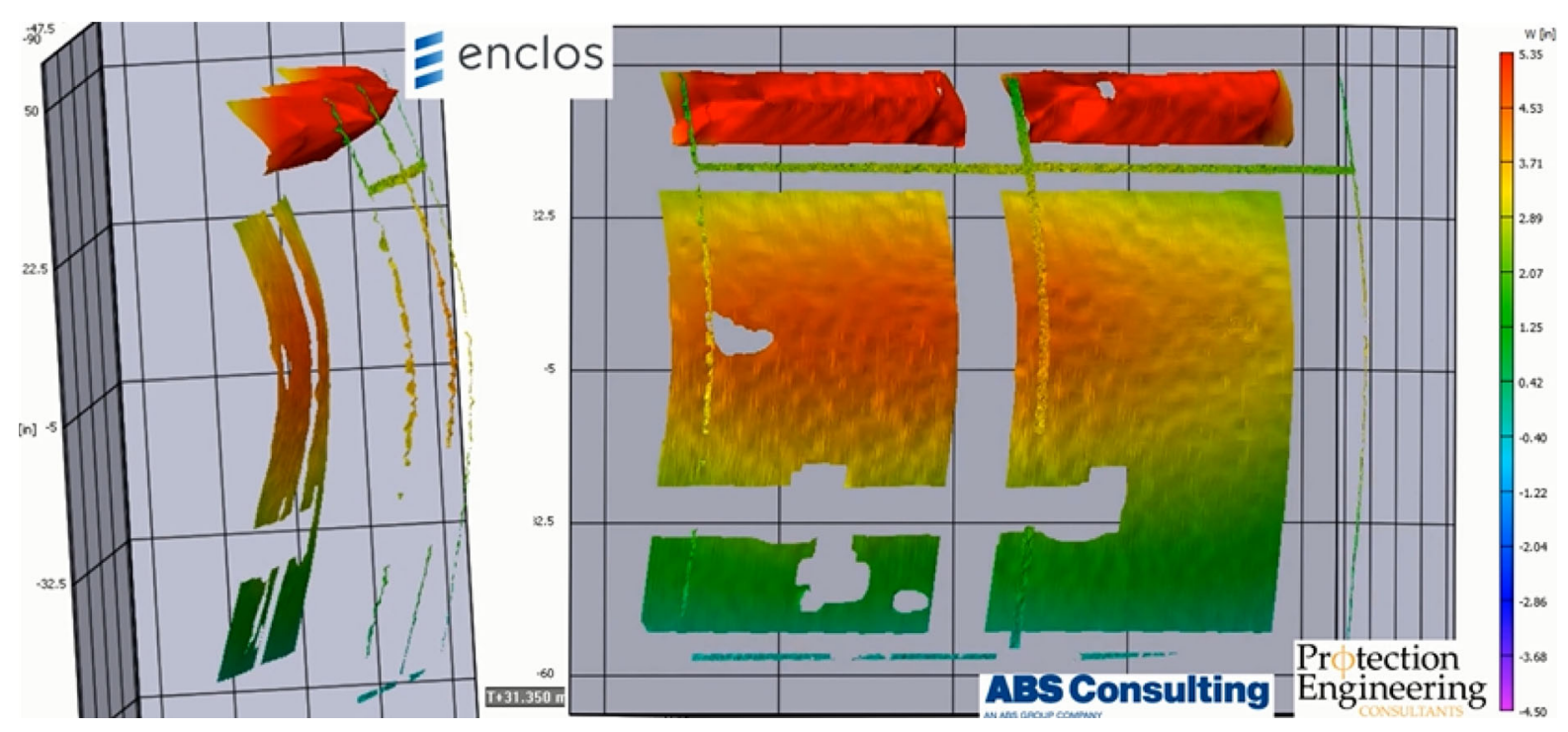

Fig. 10 Shock tube Test 4; raw DIC results [color coding refers to displacement (in.)]

Coupled system response was observed where the maximum glazing response occurred at approximately the same time as maximum mullion displacement. For example, in Test 4, maximum window response occurred around 27.7-ms (color coded displacements determined from DIC data analysis are shown in Fig. 10), while maximum mullion response occurred around 24.9-ms.

Response of each IGU is summarized in Table 3. Typical IGU response covered the range of response conditions from no glass break to glass break with PVB response. Bite failure of the lower IGU with laminate was only observed in Test 5. Maximum window response (pre-bite failure) occurred close to maximum mullion response.

Overall mullion response for all shock tube tests is summarized in Table 4. In Test 1 and 2, the vertical mullions and jambs responded elastically (with a parabolic deformed shape) and exhibited no yielding or residual displacement due to the relatively low magnitude of the applied blast loads. In Tests 3 through 5 , the vertical mullions and jambs responded elastically (parabolic deformed shape), yielded to varying degrees with web buckling, and in Test 5 formed a plastic hinge at midspan (as shown in Fig. 11), and opened up along the interlock (or split reveal) on the back face of the vertical mullion. In all tests, the head, internal horizontal mullion, and sill moved essentially as a rigid body along with the system and experienced minimal local deflection and no yielding. Maximum vertical mullion and jamb displacements are summarized in Table 5. During Test 5, the vertical mullion (2.95 $\mathrm{m}$ span) displaced $165 \mathrm{~mm}$ at midspan (a support rotation of $6.4^{\circ}$ ).

No yielding or damage was noted in any of the connections in Tests 1 through 3. During Tests 4 and 5, some yielding of washers and hook anchors was noted during post-test inspection, including almost $19 \mathrm{~mm}$ of permanent displacement of the left hook anchor at the top of the center vertical mullion in Test 5 (see Fig. 12). End reactions for each vertical mullion and jamb are summarized in Table 5. Each top reaction was determined by direct addition of the data histories from the two adjacent load cells. On average, the top center vertical mullion load cell measurements varied by $15 \%$, while the jamb measurements varied by $30 \%$. These variations suggest that torsion was present in all connections which cannot be measured by a load cell alone. The jamb utilized a $305 \mathrm{~mm}$ long steel closure plate at the top connection to allow a connection with both through-bolts, however, during field installation the steel closure plates may have attributed to some inherent torsion of the connection due to the part fit with the aluminum mullion (only one side of the closure plate was provided, thus a flipped version was used on the other side instead of the female/male counterpart). The maximum end reaction recorded at the top center vertical mullion was $124 \mathrm{kN}$ during Test 5 (see Table 5). 
Table 3 Glazing response summary

\begin{tabular}{|c|c|c|c|c|c|c|c|c|c|c|}
\hline \multirow[t]{2}{*}{ Test } & \multirow[t]{2}{*}{ Side of IGU lite } & \multicolumn{4}{|c|}{ Window response } & \multicolumn{3}{|c|}{ Measured max. response } & \multirow{2}{*}{$\begin{array}{l}\text { Bite } \\
\text { failure }\end{array}$} & \multirow[t]{2}{*}{ Debris hazard } \\
\hline & & A & B & $\mathrm{C}$ & $\mathrm{D}$ & Disp. $(m m$, in $)$ & Time (ms) & Location & & \\
\hline \multirow[t]{2}{*}{1} & Threat & NB & NB & NB & NB & $28,1.1^{\mathrm{d}}$ & 86.4 & Center of $\mathrm{C}$ & None & No \\
\hline & Protected & NB & NB & NB & NB & & & & & \\
\hline \multirow[t]{2}{*}{2} & Threat & NB & NB & NB & Break $^{\mathrm{a}}$ & $43,1.7^{\mathrm{d}}$ & 85.0 & Center of $\mathrm{C}$ & None & Yes \\
\hline & Protected & Break & Break & NB & NB & & & & & \\
\hline \multirow[t]{2}{*}{3} & Threat & Break & Break & NB & NB & $112,4.4^{\mathrm{e}}$ & 21.7 & $\begin{array}{l}\text { Upper left } \\
\text { corner D }\end{array}$ & None & Yes \\
\hline & Protected & Break & Break & NB & Break $^{b}$ & & & & & \\
\hline \multirow[t]{2}{*}{4} & Threat & Break & Break & Break & Break & $152,6.0^{\mathrm{e}}$ & 27.7 & $\begin{array}{l}\text { Upper } \\
\text { center C }\end{array}$ & None & Yes \\
\hline & Protected & Break & Break & Break $^{c}$ & Break $^{c}$ & & & & & \\
\hline \multirow[t]{2}{*}{5} & Threat & Break & Break & Break & Break & $538,21.2^{\mathrm{e}}$ & 96.9 & $\begin{array}{c}\text { Upper right } \\
\text { corner C }\end{array}$ & $\begin{array}{l}\text { C. pull } \\
\text { out } \\
\text { two } \\
\text { sides }\end{array}$ & Yes \\
\hline & Protected & Break & Break & Break $^{\mathrm{c}}$ & Break $^{\mathrm{c}}$ & & & & & \\
\hline
\end{tabular}

Glazing location (viewed from protected side; see Fig. 6):

$A$ upper left, $B$ upper right, $C$ lower left, $D$ lower right, $N B$ no break

${ }^{a}$ Crack pattern consistent with failure on rebound

${ }^{\mathrm{b}}$ Outer lite break, protected (inner) lite not break

${ }^{\mathrm{c}}$ PVB activated and stretch

${ }^{\mathrm{d}}$ From laser gauge data at center of window $\mathrm{C}$ for protected (inner) lite, absolute displacement, first inbound response not captured, shock tube movement estimated

${ }^{\mathrm{e}}$ From DIC data for protected (inner) lite, absolute displacement

Table 4 General mullion response summary

\begin{tabular}{lll}
\hline Member & Mullion response & Test \# \\
\hline Vertical mullion/jamb & No yielding or residual disp. & 1,2 \\
& Yield at midspan, open up along vertical joint & 3 \\
& Yield, open up along interlock, local buckling of web, form plastic hinge & 4,5 \\
Head/horizontal/sill & No yielding or residual disp. & $1,2,3,4,5$
\end{tabular}

\section{Window design tool modeling and validation}

PEC performed a coupled analysis of the glazing and mullions to account for the influence of flexible glazing supports using a simplified design-level finite element modeling strategy within the LS-DYNA code (consistent with WhAM design methodology). The intent of this analysis effort was not to create the most rigorous 3dimensional representation of every curtain wall specimen element, but rather to strike a balance between computational fidelity and expedience that aligns with the design-level objective of WhAM.
The multi-physics finite element code LS-DYNA was used to develop the curtain wall specimen finite element model. Design-level simplifications were made during finite element model development. They included representation of aluminum mullions as Timoshenkotype beam elements (i.e., line elements), representation of IGU glass lites, PVB interlayer material, and spacers as reduced-integration shell elements, representation of curtain wall connections as idealized single-point kinematic constraints, neglect of all IGU rubber elements, representation of mullion connections as ideal pins, representation of a laminated glass lite with lumped 
Fig. 11 Vertical mullion and jamb response-Test 5
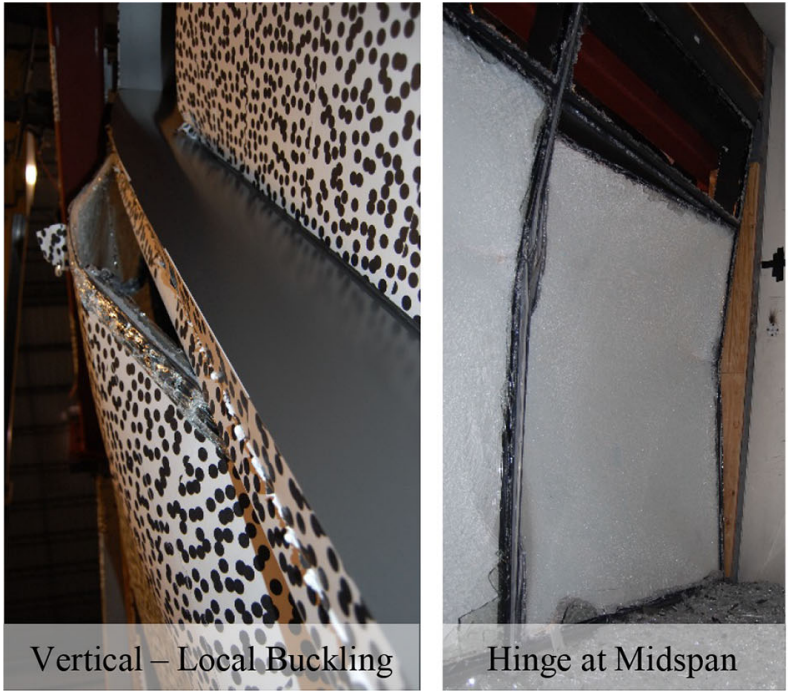

Table 5 Mullion displacement summary (viewed from protected side)

\begin{tabular}{|c|c|c|c|c|c|c|c|c|c|}
\hline \multirow[t]{2}{*}{ Test } & \multirow{2}{*}{$\begin{array}{l}\text { Load (press—kpa, psi imp- } \\
\text { kpa-ms, psi-ms) }{ }^{\mathrm{d}}\end{array}$} & \multirow[t]{2}{*}{ Member } & \multirow{2}{*}{$\begin{array}{l}\text { Span } \\
(\mathrm{m})\end{array}$} & \multirow{2}{*}{$\begin{array}{l}\text { Trib. } \\
\text { width }(\mathrm{m})\end{array}$} & \multicolumn{3}{|c|}{ Measured max. response } & \multicolumn{2}{|c|}{ Meas. end reaction } \\
\hline & & & & & $\begin{array}{l}\text { Disp. } \\
(\mathrm{mm}, \text { in })\end{array}$ & $\begin{array}{l}\text { Time } \\
(\mathrm{ms})\end{array}$ & $\begin{array}{l}\text { Location }^{\mathrm{c}} \\
(\mathrm{m}, \mathrm{ft})\end{array}$ & $\begin{array}{l}\text { Top } \\
\text { (kN, kip) }\end{array}$ & $\begin{array}{l}\text { Bottom } \\
\text { (kN, kip) }\end{array}$ \\
\hline \multirow[t]{3}{*}{$1^{\mathrm{a}}$} & \multirow[t]{3}{*}{$33.1,4.8152 .4,22.1$} & Left jamb & 2.95 & 0.79 & $18,0.7$ & 85.3 & $1.50,4.92$ & $19,4.3$ & - \\
\hline & & Vertical & 2.95 & 1.59 & $18,0.7$ & 80.0 & $1.50,4.92$ & $32,7.2$ & $28,6.4$ \\
\hline & & Right jamb & 2.95 & 0.79 & - & - & - & $17,3.9$ & $15,3.4$ \\
\hline \multirow[t]{3}{*}{$2^{\mathrm{a}}$} & \multirow[t]{3}{*}{$58.6,8.5264 .8,38.4$} & Left jamb & 2.95 & 0.79 & $23,0.9$ & 86.0 & $1.50,4.92$ & $38,8.5$ & - \\
\hline & & Vertical & 2.95 & 1.59 & $23,0.9$ & 87.5 & $1.50,4.92$ & $56,12.5$ & $54,12.1$ \\
\hline & & Right jamb & 2.95 & 0.79 & - & - & - & $40,9.1$ & $35,7.8$ \\
\hline \multirow[t]{3}{*}{$3^{\mathrm{b}}$} & \multirow[t]{3}{*}{$80.0,11.6416 .4,60.4$} & Left jamb & 2.95 & 0.79 & $89,3.5$ & 24.9 & $1.50,5.42$ & $80,18.0$ & - \\
\hline & & Vertical & 2.95 & 1.59 & $84,3.3$ & 23.2 & $1.52,5.00$ & $85,19.0$ & $80,17.9$ \\
\hline & & Right jamb & 2.95 & 0.79 & $69,2.7$ & 27.4 & $1.52,5.00$ & $69,15.5$ & $51,11.5$ \\
\hline \multirow[t]{3}{*}{$4^{\mathrm{b}}$} & \multirow[t]{3}{*}{$100.7,14.6530 .2,76.9$} & Left jamb & 2.95 & 0.79 & $112,4.4$ & 23.7 & $1.68,5.50$ & $81,18.2$ & - \\
\hline & & Vertical & 2.95 & 1.59 & $130,5.1$ & 24.9 & $1.73,5.67$ & $112,25.1$ & $86,19.4$ \\
\hline & & Right jamb & 2.95 & 0.79 & $109,4.3$ & 23.7 & $1.68,5.50$ & $98,22.0$ & $67,15.0$ \\
\hline \multirow[t]{3}{*}{$5^{\mathrm{b}}$} & \multirow[t]{3}{*}{$112.4,16.3742 .6,107.7$} & Left jamb & 2.95 & 0.79 & $147,5.8$ & 34.0 & $1.52,5.00$ & $98,22.0$ & - \\
\hline & & Vertical & 2.95 & 1.59 & $165,6.5$ & 27.3 & $1.56,5.13$ & $124,27.9$ & $100,22.4$ \\
\hline & & Right jamb & 2.95 & 0.79 & $152,6.0$ & 33.0 & $1.50,5.42$ & $107,24.1$ & $82,18.4$ \\
\hline
\end{tabular}

Span $2.95 \mathrm{~m}$, tributary width vertical $1.58 \mathrm{~m}$, tributary width jamb $0.79 \mathrm{~m}$

${ }^{a}$ Deflection data from laser gauge, first inbound response not captured, shock tube movement estimated

${ }^{b}$ Deflection data from DIC (preferred measurement method)

${ }^{c}$ Measured from bottom of mullion

${ }^{\mathrm{d}}$ Load shapes were all essentially triangular (linear decay); subsequent shock tube reflections were made up of waves with amplitude

$<10 \%$ of the peaks observed, and subsequent reflections typically added $<5 \%$ of the total applied impulse 
Fig. 12 Vertical mullion connection responseTest 5

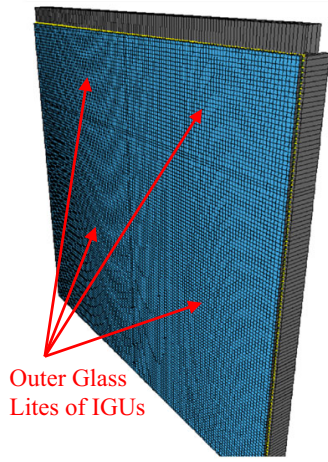

(a)

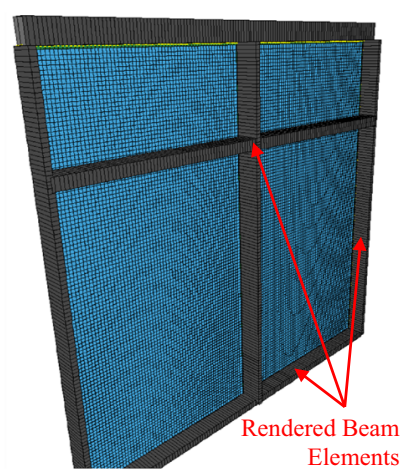

(b)

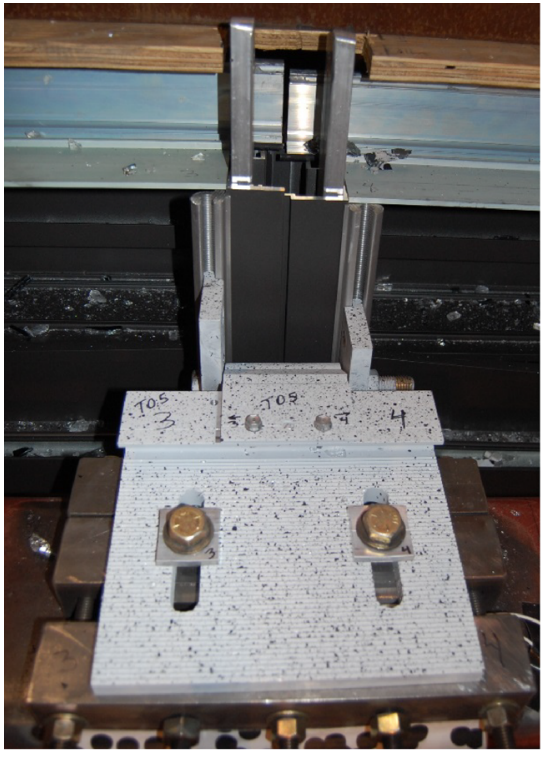

Test 5: Left "hook" anchor displaced $\sim 3 / 4$-in
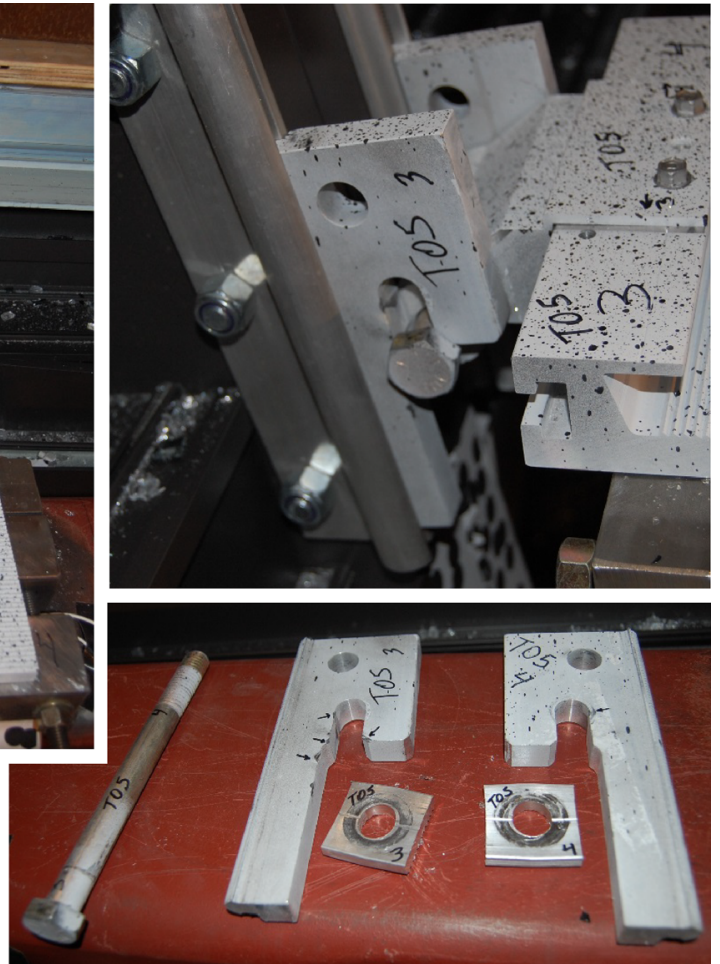

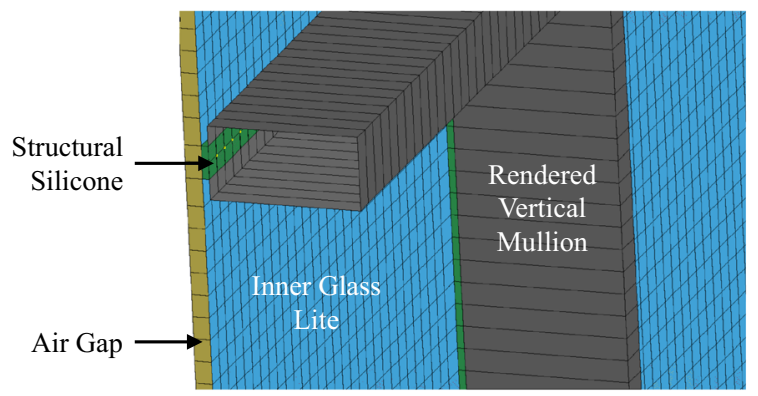

Fig. 14 Illustration of finite element details along vertical crosssection through centerline of curtain wall specimen IGUs

Isometric views of the curtain wall finite element model are presented in Figs. 13 and 14, where both the blast-loaded face of the specimen (inside the shock tube) and the protected face of the specimen (outside the shock tube) are shown in Fig. 13. It can be seen in Fig. 14 that structural silicone and the IGU air gaps were both represented with constant stress (i.e., single integration point) solid elements, which is the default and most widely used (and most robust) hexahedron element in LS-DYNA. Constitutive behavior of the air gap elements was represented with a null material model and an ideal-gas equation of state. The null 


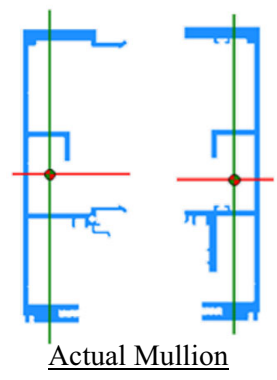

Section

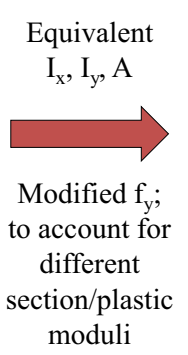

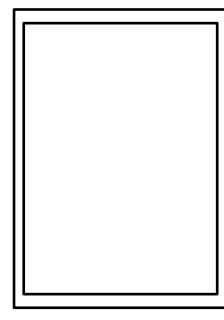

Equivalent Mullion Section

Fig. 15 Mullion equivalent beam elements

material model retained the mass characteristics of air while necessarily disallowing any deviatoric strength, and the ideal-gas equation of state captured appropriate hydrostatic pressure-volume behavior exhibited by air. Combination of the null material model and ideal-gas equation of state was shown to adequately capture the dynamic behavior of an IGU air gap as it compresses and transfers load between glass lites during the blast response of a curtain wall system. Constitutive behavior of the structural silicone was represented with a hyper-elastic material model calibrated to test data for the Dow Corning 995 structural silicone product (Dow Corning 2009). Coincident nodes of the hexahedron air gap elements, glass lite shell elements, and aluminum spacer shell elements were merged to facilitate the connectivity of an IGU unit. Constitutive behavior of the PVB interlayer for laminated glass lites was represented with a nonlinear plasticity model that was calibrated based on previously collected test data (USACE 2012; Schneider et al. 2012).

In representing aluminum mullions with beam elements, equivalent cross sections were first derived. As is graphically depicted in Fig. 15, an equivalent rectangular tube section with unequal side thicknesses was derived for each aluminum mullion section. The derivation was carried out by solving a set of simultaneous equations such that the equivalent rectangular tube section possessed the same cross-sectional area, strongaxis moment of inertia, and weak-axis moment of inertia as those of the actual mullion cross section. The main drawback of this equivalency was that the rectangular tube section was not able to replicate the torsional properties of the actual mullion cross section, nor did it possess the same section/plastic moduli of the actual mullion cross section. Nothing was done to address the torsional discrepancy. However, the flexural strength

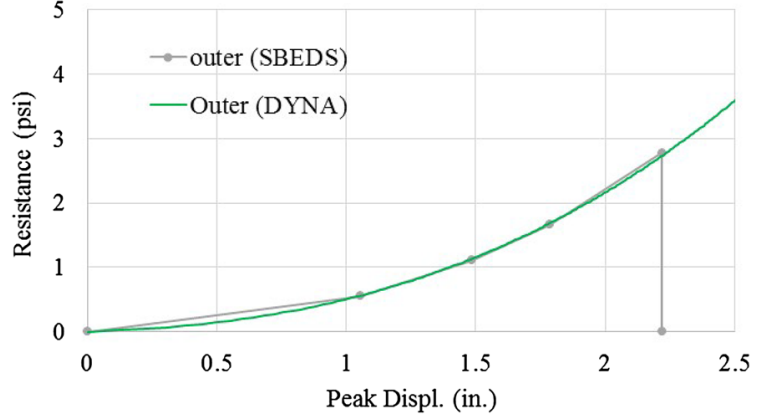

Fig. 16 SBEDS-W/GFPM model for threat-side (outer) lite of lower IGU-resistance function comparison

discrepancy was ameliorated by artificially adjusting the equivalent section's static yield strength to account for the difference in section/plastic moduli. Section and plastic modular ratios between the actual and equivalent sections were calculated and averaged. The average ratio was then used to artificially adjust the equivalent section's nominal yield strength. The resulting constitutive behavior of the aluminum mullions was represented with a nonlinear plasticity model that was calibrated based on nominal data for 6063-T6 aluminum and adjusted as described above to better replicate an actual mullion section's yield moment. Constitutive behavior of the IGU spacers was represented with the same baseline aluminum material model and no static yield strength modification. Strain-rate effects were explicitly accounted for within the constitutive model using the Cowper-Symonds relationship (Cowper and Symonds 1958) and appropriate empirical coefficients for 6063-T6 aluminum.

For the purpose of predicting glass break during the computational simulations, a preliminary glass-break methodology was employed. The methodology was based on the Glass Failure Prediction Model (GFPM) as implemented in SBEDS-W. SBEDS-W generates resistance functions for each glass lite, which are not directly applicable to a finite element analysis. Thus, the resistance function output from SBEDS-W had to be utilized to ultimately determine a material-level (i.e., a stress or strain quantity) failure criterion for the glass. Quasi-static simulations of a transversely loaded single lite of glass were first performed in LSDYNA to replicate the SBEDS-W resistance functions. An example of this resistance function matching exercise is shown in Fig. 16 for the SBEDS-W lower IGU threat-side (outer) glass lite. For this comparison, the material behavior 

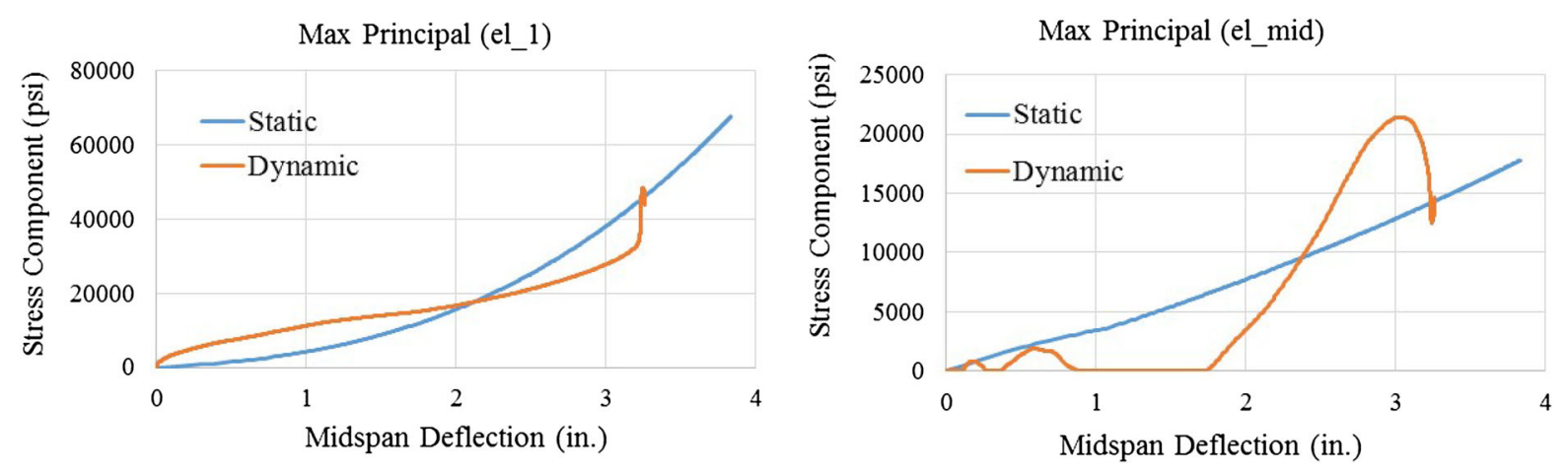

Fig. 17 SBEDS-W/GFPM model for threat-side (outer) lite of lower IGU—static and dynamic principal stress comparisons at corner (left) and center (right) of glass lite

for glass is represented with a linear elastic constitutive model. The LS-DYNA results confirm that geometric nonlinearity (when membrane stresses begin to develop as glass lite transverse displacement becomes larger than its thickness) can be adequately captured. During the quasi-static simulations, various stress component histories were recorded at the center of the glass lite and at various locations along a $45^{\circ}$. diagonal from a corner of the glass lite. A series of dynamic simulations were also conducted for all considered glass lites, to compare stress component histories with those from the quasi-static simulations. During the dynamic analyses, the load input consisted of a right-triangular pulse having a peak pressure of $30.3 \mathrm{kPa}$ and a specific impulse of $213.7 \mathrm{kPa}$.

After reviewing maximum/minimum principal stress and maximum shear stress component histories for the various simulations, it was determined that developing a glass-break criterion based on maximum principal stress was most appropriate. Example static/dynamic maximum principal stress history comparisons for corner (left) and central (right) elements are shown in Fig. 17 for the SBEDS-W lower IGU threat-side (outer) glass lite.

Ultimately, the maximum principal stress at glassbreak was defined as the absolute maximum principal stress that occurred during the quasi-static simulation and at the SBEDS-W glass-break deflection. To be compatible with the SBEDS-W resistance functions, quasi-static stresses had to be used. This stressbased glass failure approach resulted in slightly different glass-break stresses among the various glass lites for SBEDS-W. In general, maximum principal stress in the corner element was found to control the 2-way

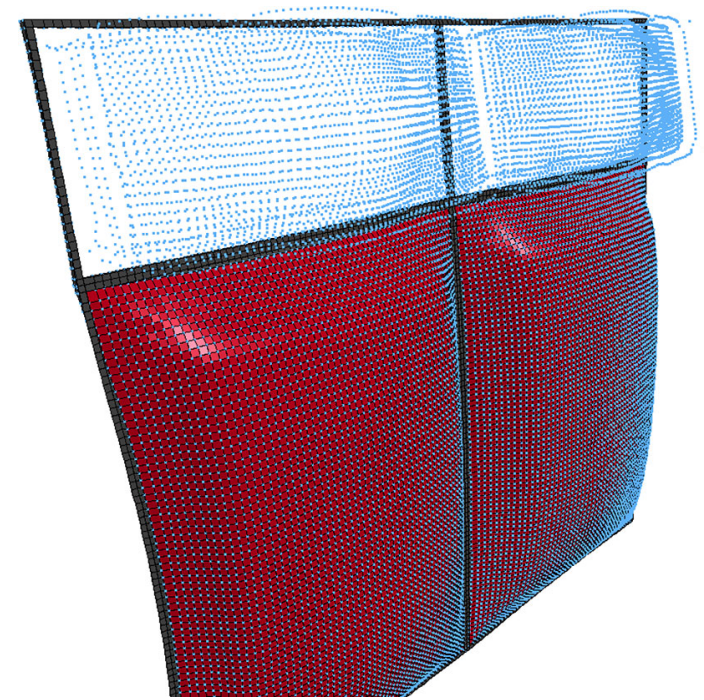

Fig. 18 FEA representation of glass-break methodology in LSDYNA

spanning lower IGU glass lites, while maximum principal stress in the central element was found to control the 1-way spanning upper IGU glass lites.

The physical representation of glass-break during the computational simulations is shown in Fig. 18. Once the maximum principal stress corresponding to glass break is reached, the entire computational part representing the failed glass lite is instantaneously removed from the computational domain. However, nodes of the failed finite elements are retained, and the mass of the failed finite elements is appropriately partitioned to the retained nodes based on tributary areas. As can be seen in Fig. 18, retained nodes from a failed monolithic glass lite simply fly off into 
space as glass shards; whereas, retained nodes from a failed laminated glass lite transfer momentum of the glass shards to the PVB interlayer via the previously described kinematic-constraint-based tied contact definition.

\subsection{Glazing response comparisons}

An abbreviated comparison of measured versus various kinematic response history comparisons from the finite element simulations is included in this section.

A comparison of the Test 1 lower IGU laser gauge displacement history with that predicted in LS-DYNA is shown in Fig. 19. It should be noted that the laser gauge trigger was not working properly during Test 1 , thus the measured data essentially begins at the IGUs second inbound incursion. Two computational predictions are shown in Fig. 19. The light blue curve represents the predicted displacement history when no structural damping is considered in computational space, and the dark blue curve represents the predicted displacement history when $7 \%$ structural damping is considered. A structural damping ratio of $7 \%$ was ascertained from the free vibration portion of the Test 1 laser gauge displacement history using the Logarithmic Decrement technique (Thomson and Dahleh 1997). Note that the second inbound and rebound peaks of the damped displacement history are in good agreement with those of the measured data, thus implying that the first inbound and rebound peaks are likely in agreement as well. Accordingly, $7 \%$ structural damping was included in the computational model of the curtain wall specimen for all subsequent simulations.

A comparison of the Test 3 lower IGU laser gauge displacement history with that predicted in LS-DYNA is shown in Fig. 20. Three computational predictions are shown in Fig. 20. The dark blue curve represents the predicted displacement history when no glassbreak is permitted. The green curve represents the predicted displacement history when the GFPM glassbreak methodology is permitted, and the black curve represents the predicted displacement history when no glass-break is permitted and no vertical restraint is provided at the specimen support locations. During the glass-break-permitted simulation, the protected (inner) lite of the lower-left IGU broke early in time before the $16-m s$ blast pulse was done acting on the specimen. The result of this simulation was a poor prediction of glaz- ing response. The predicted glazing response for the no-break and no-break with no vertical restraint simulations both yielded much better results with respect to glass lite first inbound and rebound peak responses. Very little difference was observed between the nobreak and no-break with no vertical restraint simulations. No vertical restraint was evaluated due to the ability of the top connections to flex in the vertical direction, which was observed in later tests. Rather than quantifying the connection's vertical stiffness and incorporating that into the computational model, vertical restraint at the connection points was completely removed. This was an easy simplification to implement in the computational model, which revealed the influence of vertical connection flexibility on glazing and mullion response.

Test 3 DIC results were also compared with the finite element no-break simulation results. The comparison to DIC results was made by taking horizontal cuts through the mid-span of the lower IGUs (Section AA) and upper IGUs (Section BB), taking a vertical cut through the mid-span of both IGUs (Section CC), and plotting several deformation curves about these cuts at various times during the specimen response. The Test 3 Section AA deformation curves are shown in Fig. 21. While the deformation shape of the lower IGUs in Fig. 25 were predicted fairly well by the finite element model, it can be seen that the predicted magnitudes were ahead of the measured magnitudes early in time. By 20-ms into the response, the finite element deformation curve agrees well with the DIC deformation curve. In addition, it can be observed that the vertical mullion response was captured fairly well with the finite element model. It is currently unknown why the finite element deformation magnitudes were consistently greater than those measured with the DIC instrumentation. One theory is that inertial resistance of the glass lites due to early-time acceleration of the entire shock tube assembly could have contributed to the difference in early-time displacement magnitude. While the post-processed test data were corrected for the measured movement of the shock tube apparatus, the inertial effects associated with the shock tube movement were not explicitly captured during the finite element simulations. Difficult to measure slippage in the connections would also contribute to the apparent initial resistance.

The Test 3 Section BB deformation curves are shown in Fig. 22, where the same early-time trend observed at the Section AA cut was also observed at the Sec- 
Fig. 19 FEA glazing response comparison-Test 1 , laser gauge 3
Fig. 20 FEA glazing response comparison-Test 3 , laser gauge 3
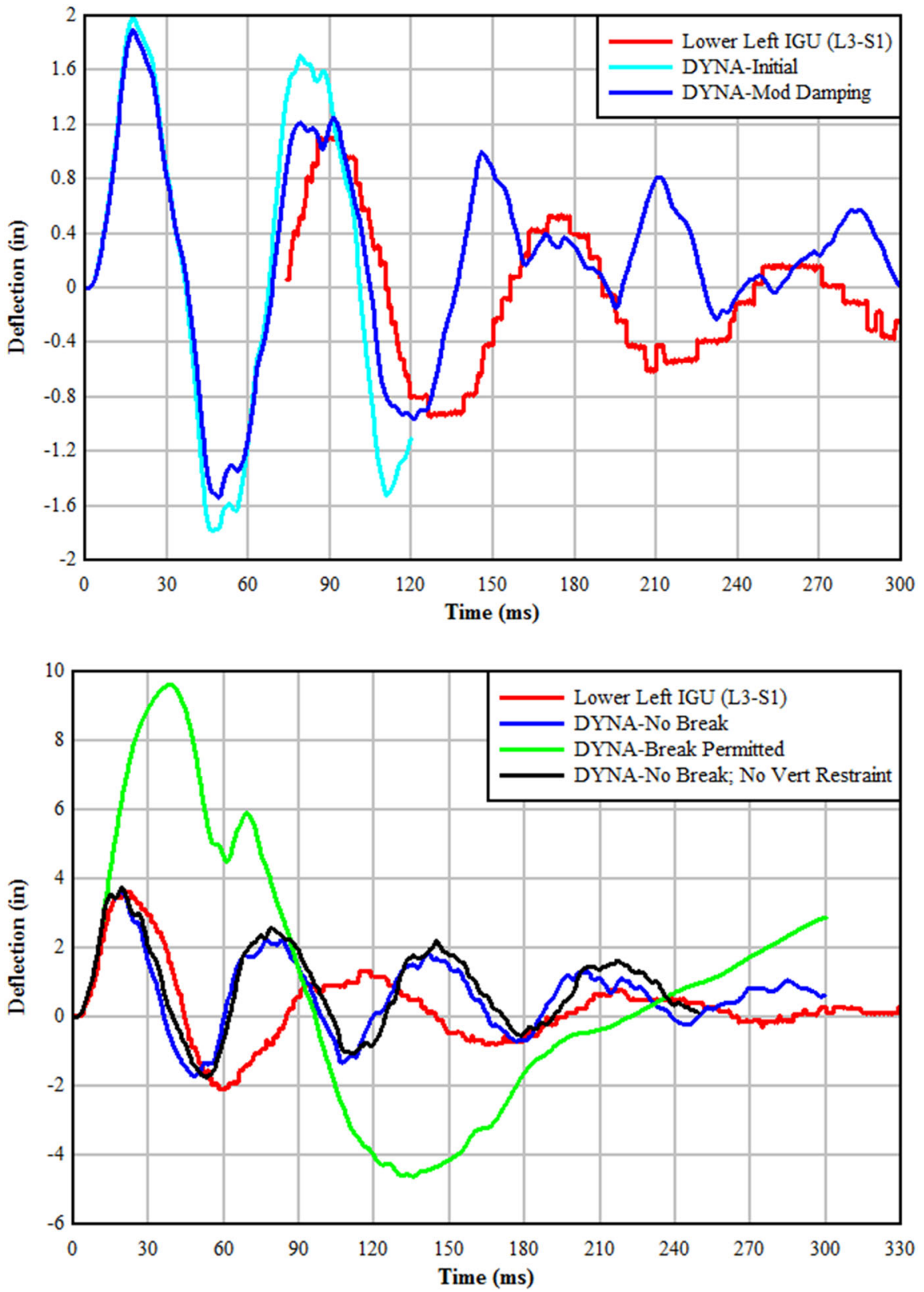

tion BB cut up until glass failure. In Fig. 22, the 20-ms predicted deformation curve shows rebound because glass-break was not permitted during the simulation; whereas, actual glass failure was observed between 6$\mathrm{ms}$ and 10-ms. The Test 3 Section CC deformation curves are shown Fig. 23. The same early-time trend can also be observed in Fig. 23. It is interesting to note in Fig. 23 that the shape of the $10-\mathrm{ms}$ and $20-\mathrm{ms}$ pre- dicted deformation curves follow reasonably well with the measured deformation shapes.

A comparison of the Test 5 lower IGU laser gauge displacement history with that predicted in LS-DYNA is shown in Fig. 24. Three computational predictions are shown in Fig. 24. The dark blue curve represents the predicted displacement history when no glassbreak is permitted. The green curve represents the predicted displacement history when the GFPM glass- 
Fig. 21 FEA glazing response comparisonTest 3 DIC, Section AA, no glass-break permitted
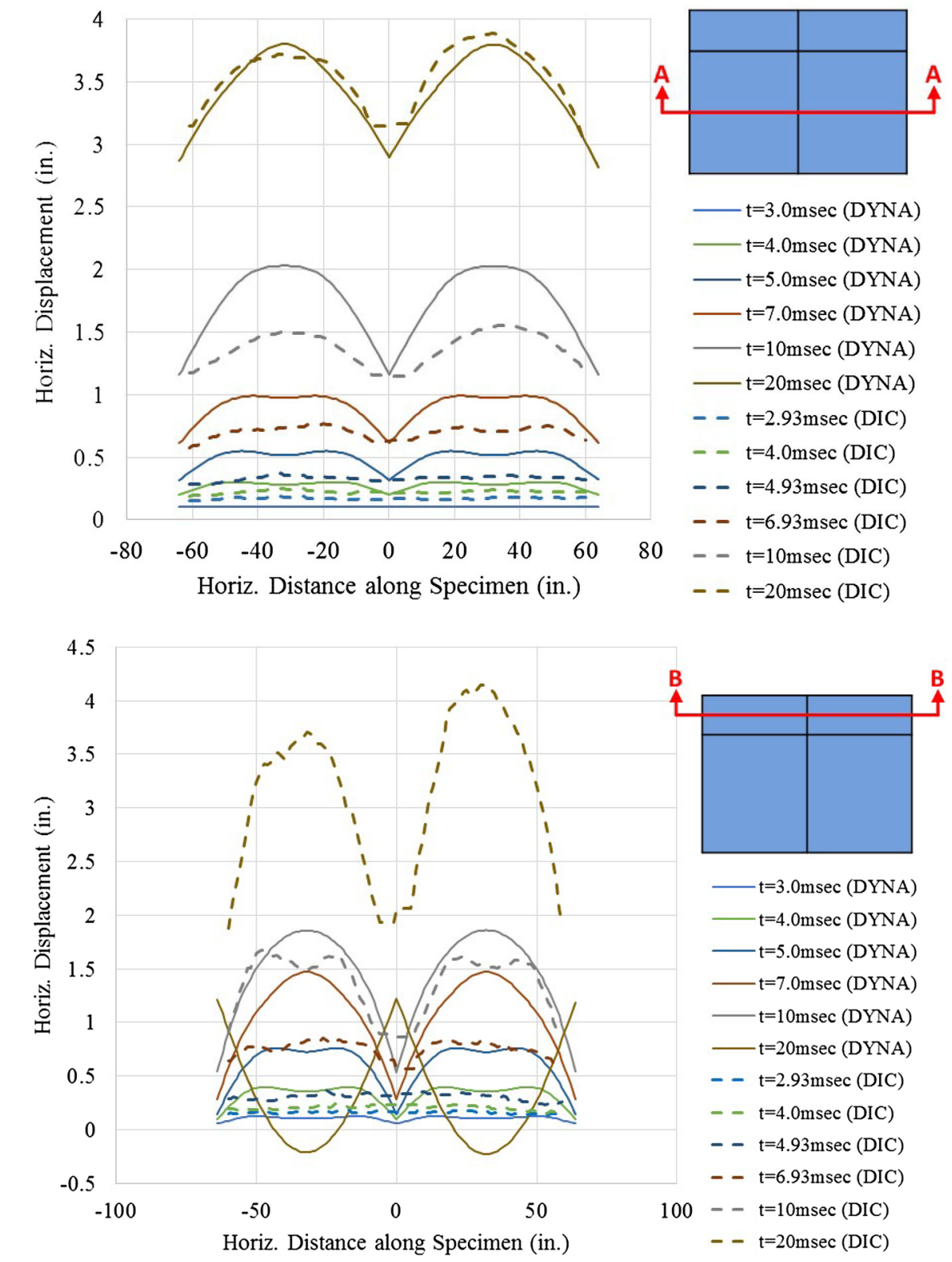

Fig. 22 FEA glazing response comparisonTest 3 DIC, Section BB, no glass-break permitted break methodology is permitted, and the black curve represents the predicted displacement history when no glass-break is permitted and no vertical restraint is provided at the specimen support locations. During Test 5 , the protected (inner) lite of the lower-left IGU was observed to crack with associated PVB stretching and moderate tearing. At the top of the lower-left IGU, the PVB pulled out of the frame entirely. Due to the level of damage sustained by the protected (inner) lite of the lower-left IGU during Test 5, both the no-break and no-break with no vertical restraint simulations resulted in poor glazing response predictions. As was the case for the previously discussed tests, glass-break occurred prematurely during the break-permitted simulation. However, glass-break also occurred relatively early during the test. As such, the break-permitted simulation yielded the best peak glazing response prediction at approximately $394 \mathrm{~mm}$ ( $15.5 \mathrm{in})(\sim 25 \%$ overprediction). 
Fig. 23 FEA glazing response comparisonTest 3 DIC, Section CC, no glass-break permitted

Fig. 24 FEA glazing response comparisonTest 5 , laser gauge 3
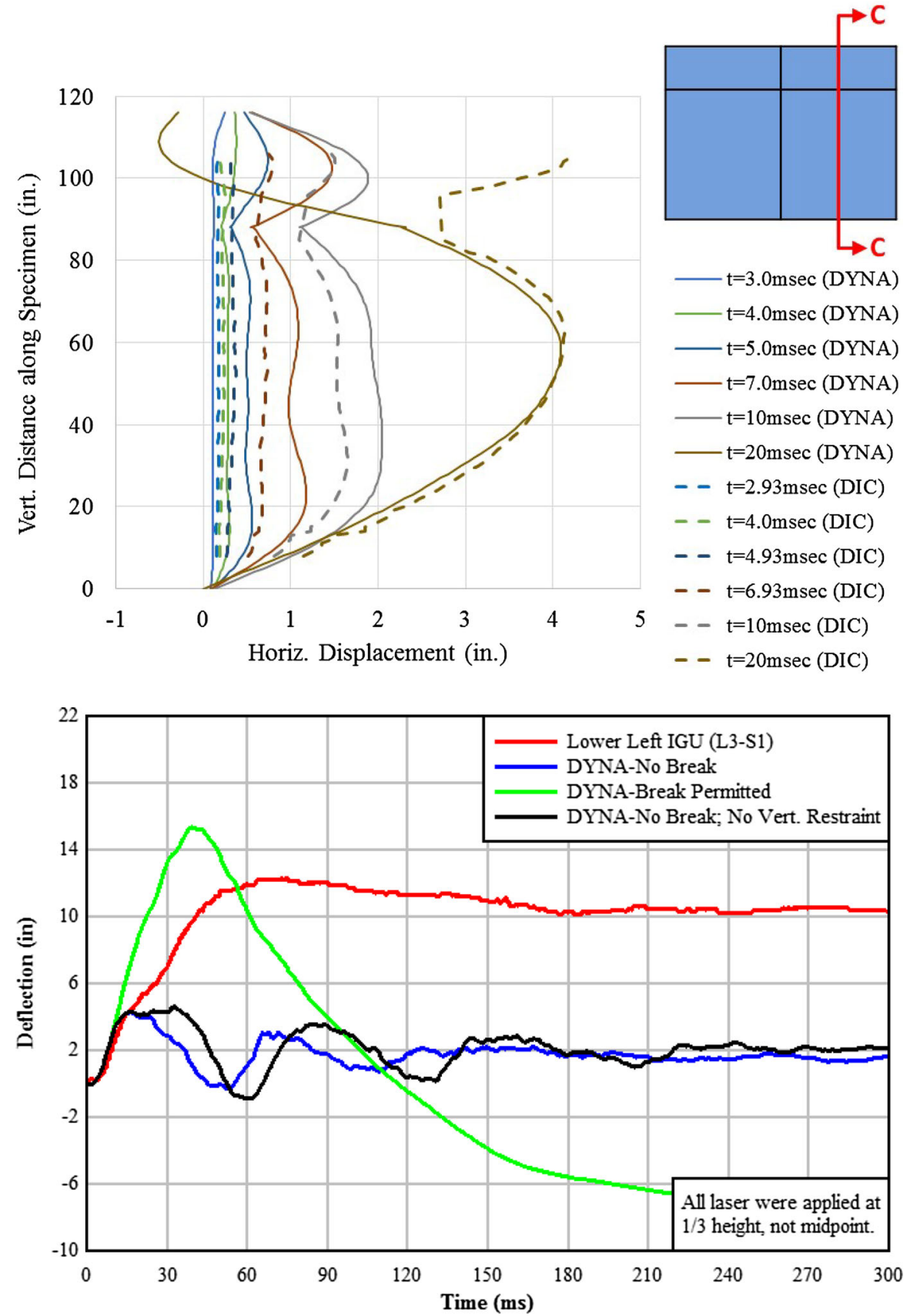

Test 5 DIC results were also compared with the finite element no-break and break-permitted simulation results. The Test 5 Section AA deformation curves for the no-break and break-permitted simulations are shown in Figs. 25 and 26, respectively. In both Figs. 25 and 26 , the previously mentioned early-time deformation magnitude discrepancy can be observed again. In
Fig. 25, it can be seen that vertical mullion response is captured quite well up to $20-\mathrm{ms}$, as is glazing response (glass-break likely occurred around 20-ms). In Fig. 26, the break-permitted simulation exhibits excessive PVB response at 20-ms due to premature glass-break.

The Test 5 Section BB deformation curves for the no-break and break-permitted simulations are shown 
Fig. 25 FEA glazing response comparisonTest 5 DIC, Section AA, no glass-break permitted

Fig. 26 FEA Glazing response comparisonTest 5 DIC, Section AA, GFPM gass-break permitted
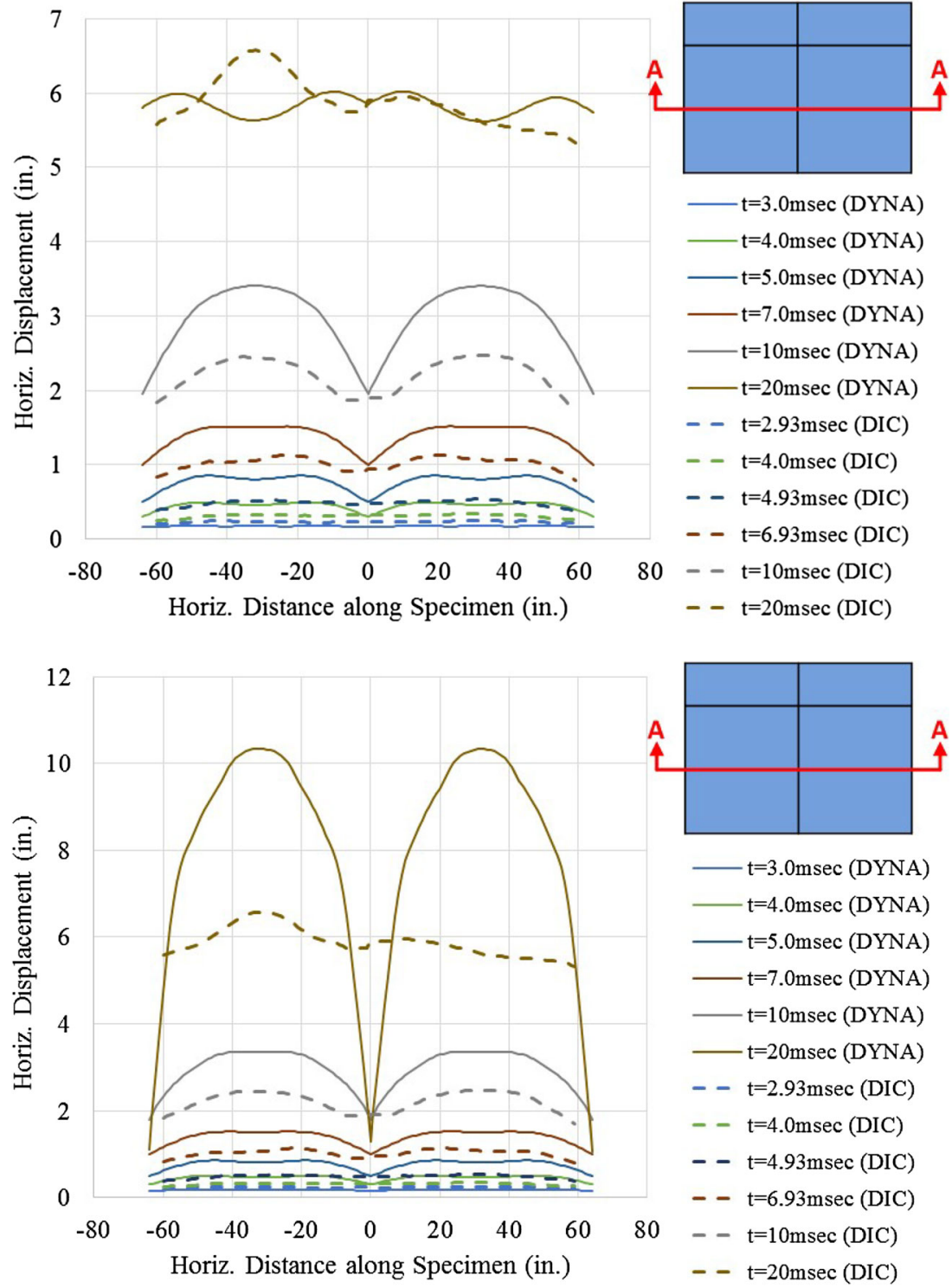

in Figs. 27 and 28, respectively. Figure 27 illustrates that the early-time deformation magnitude discrepancy is present and the predicted 20-ms deformation curve shows rebound because glass-break was not permitted. For the break-permitted simulation, Fig. 28 shows that computational glass-break occurred between 3- and 5ms. Based on high-speed video, it appears as though actual glass-break in the upper IGUs occurred around 7-ms. Aside from the early-time deformation magnitude discrepancy (likely due to inertial effects associated with shock tube acceleration), the break-permitted glazing response predictions for the upper IGUs align reasonably well with the measured response-within
$12.7 \mathrm{~mm}$ for most of the time steps. Again, it should be recalled that the post-break deformation curves shown in Fig. 28 represent null shell elements. The null shell elements have no physical meaning with respect to post-break glass response, and they serve the sole purpose of facilitating contact between the different elements of the IGU unit.

The Test 5 Section CC deformation curves for the no-break and break-permitted simulations are shown in Figs. 29 and 30, respectively. In summary, the trends and observations previously noted for the Test $5 \mathrm{Sec}$ tion $\mathrm{AA}$ and $\mathrm{BB}$ deformation curves can also be seen in the Section CC plots. Most notably, in Fig. 29, it 
Fig. 27 FEA glazing response comparison-Test 5 DIC, Section BB, no glass-break permitted

Fig. 28 FEA glazing response comparison-Test 5 DIC, Section BB, GFPM glass-break permitted
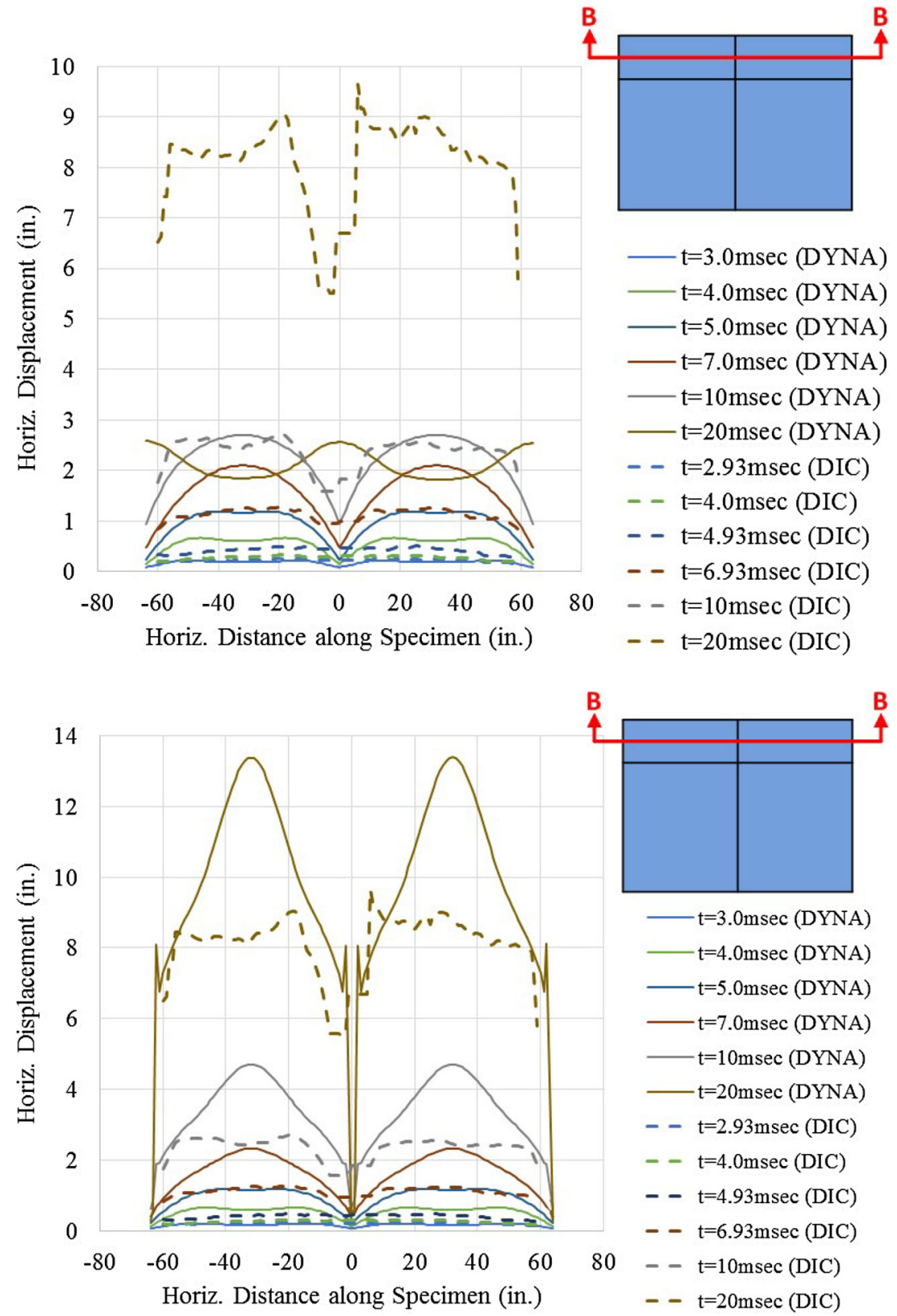

can be seen that horizontal mullion response is being predicted quite well up to 20 -ms. Though slightly overpredicted, the shape of the predicted lower IGU deformation curves align well with those measured with the DIC instrumentation. In Fig. 30, the predicted lower IGU deformation curve at 20-ms is notably larger than that measured with the DIC instrumentation because glass-break occurred prematurely during the simulation.

\subsection{Mullion response comparisons}

An abbreviated comparison of measured versus predicted mullion response is provided in this section, including tabular peak displacement comparisons with finite element simulation results, as well as various kinematic response history comparisons for the finite element simulations. 
Fig. 29 FEA glazing response comparison-Test 5 DIC, Section CC, no glass-break permitted

Fig. 30 FEA glazing response comparison-Test 5 DIC, Section CC, GFPM glass-break permitted
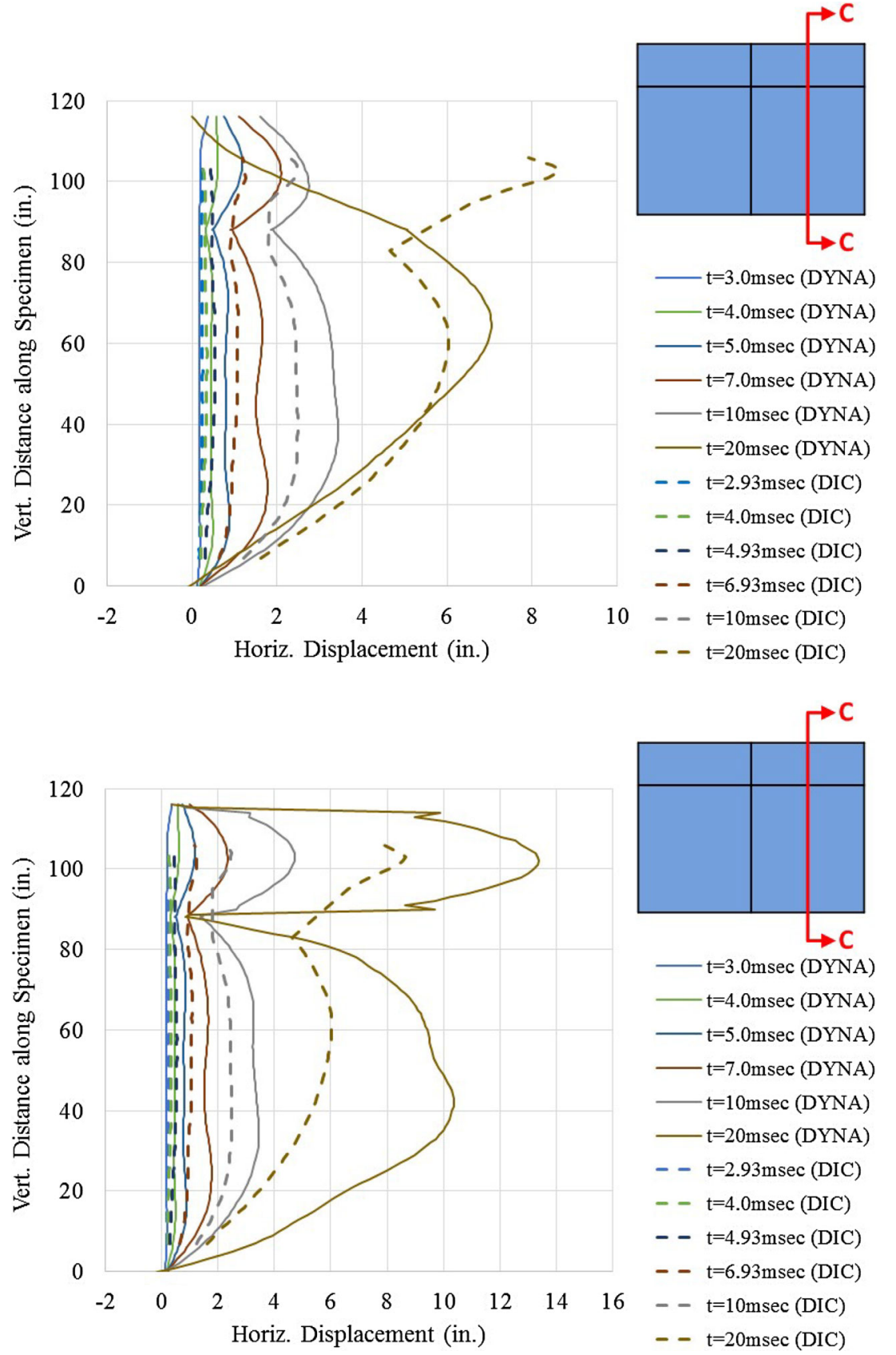

A comparison of measured and finite element simulation predicted peak mullion responses is reported in Table 6.

The vertical mullion and jamb response predicted by LS-DYNA when no glass-break is permitted and no vertical restraint is provided at the specimen support locations is on average less than $15 \%$ in error relative to the measured DIC and laser gauge data. The design-level finite element model accounts for coupled system response and more accurately distributes load from each window to the supporting mullions.

A comparison of the Test 1 left jamb and vertical mullion laser gauge displacement histories with those predicted in LS-DYNA is shown in Figs. 31 and 32, respectively. It should be noted that the laser gauge trigger was not working properly during Test 1 , thus 
Table 6 Comparisons of measured and predicted aluminum mullion response

\begin{tabular}{|c|c|c|c|c|c|c|c|}
\hline \multirow[t]{2}{*}{ Test } & \multirow[t]{2}{*}{ Design tool } & \multicolumn{3}{|c|}{ Vertical mullion } & \multicolumn{3}{|c|}{ Jamb (left/right) } \\
\hline & & Rotation $\left(^{\circ}\right)$ & Ductility $^{\mathrm{e}}$ & Disp. (mm, in) & Rotation $\left(^{\circ}\right)$ & Ductility $^{\mathrm{e}}$ & Disp. (mm, in) \\
\hline \multirow[t]{2}{*}{1} & Measured $^{\mathrm{a}}$ & 0.7 & 0.6 & $20,0.8$ & 0.7 & 0.5 & $18,0.7$ \\
\hline & WhAM (no break) & 0.8 & 0.6 & $20,0.8$ & 0.8 & 0.6 & $20,0.8$ \\
\hline \multirow[t]{3}{*}{2} & Measured $^{\mathrm{a}}$ & 0.9 & 0.7 & $23,0.9$ & 0.9 & 0.8 & $23,0.9$ \\
\hline & WhAM (break) & 1.3 & 1.0 & $33,1.3$ & 1.2 & 1.0 & $33,1.3$ \\
\hline & WhAM (no break) & 1.6 & 1.3 & $41,1.6$ & 1.5 & 1.2 & $38,1.5$ \\
\hline \multirow[t]{4}{*}{3} & Measured $^{3}$ & 3.3 & 2.6 & $84,3.3$ & 3.5 & 2.9 & $89,3.5$ \\
\hline & WhAM (break) & 1.6 & 1.3 & $41,1.6$ & 1.5 & 1.3 & $41,1.6$ \\
\hline & WhAM (no break) & 3.0 & 2.4 & $76,3.0$ & 2.9 & 2.4 & $74,2.9$ \\
\hline & WhAM $(\mathrm{NB} \text { or VR })^{\mathrm{d}}$ & 3.3 & 2.6 & $84,3.3$ & 3.2 & 2.6 & $81,3.2$ \\
\hline \multirow[t]{4}{*}{4} & Measured $^{\mathrm{c}}$ & 5.0 & 4.1 & $130,5.1$ & 4.3 & 3.6 & $112,4.4$ \\
\hline & WhAM (break) & 1.9 & 1.6 & $51,2.0$ & 1.9 & 1.6 & $48,1.9$ \\
\hline & WhAM (no break) & 4.1 & 3.3 & $104,4.1$ & 4.1 & 3.4 & $102,4.0$ \\
\hline & WhAM $\left(\mathrm{NB}\right.$ or VR) ${ }^{\mathrm{d}}$ & 4.8 & 3.9 & $124,4.9$ & 4.7 & 3.9 & $119,4.7$ \\
\hline \multirow[t]{4}{*}{5} & Measured $^{c}$ & 6.4 & 5.2 & $165,6.5$ & 5.7 & 4.8 & $147,5.8$ \\
\hline & WhAM (break) & 2.1 & 1.7 & $53,2.1$ & 2.1 & 1.7 & $51,2.0$ \\
\hline & WhAM (no break) & 5.4 & 4.4 & $140,5.5$ & 5.4 & 4.5 & $140,5.5$ \\
\hline & WhAM $\left(\mathrm{NB}\right.$ or VR) ${ }^{\mathrm{d}}$ & 7.2 & 5.8 & $185,7.3$ & 7.2 & 5.9 & $180,7.1$ \\
\hline
\end{tabular}

a Second inbound response measured, laser gauge data

${ }^{b}$ Prediction of second inbound response shown because first inbound response not measured

${ }^{c}$ DIC data

${ }^{\mathrm{d}} N B$ or $V R$ no break or vertical restraint (upper bound response)

e Yield displacement estimated from SDOF analysis ( $32 \mathrm{~mm}$ for vertical, $31 \mathrm{~mm}$ for jambs)

Fig. 31 FEA mullion response comparisonTest 1 , laser gauge 1

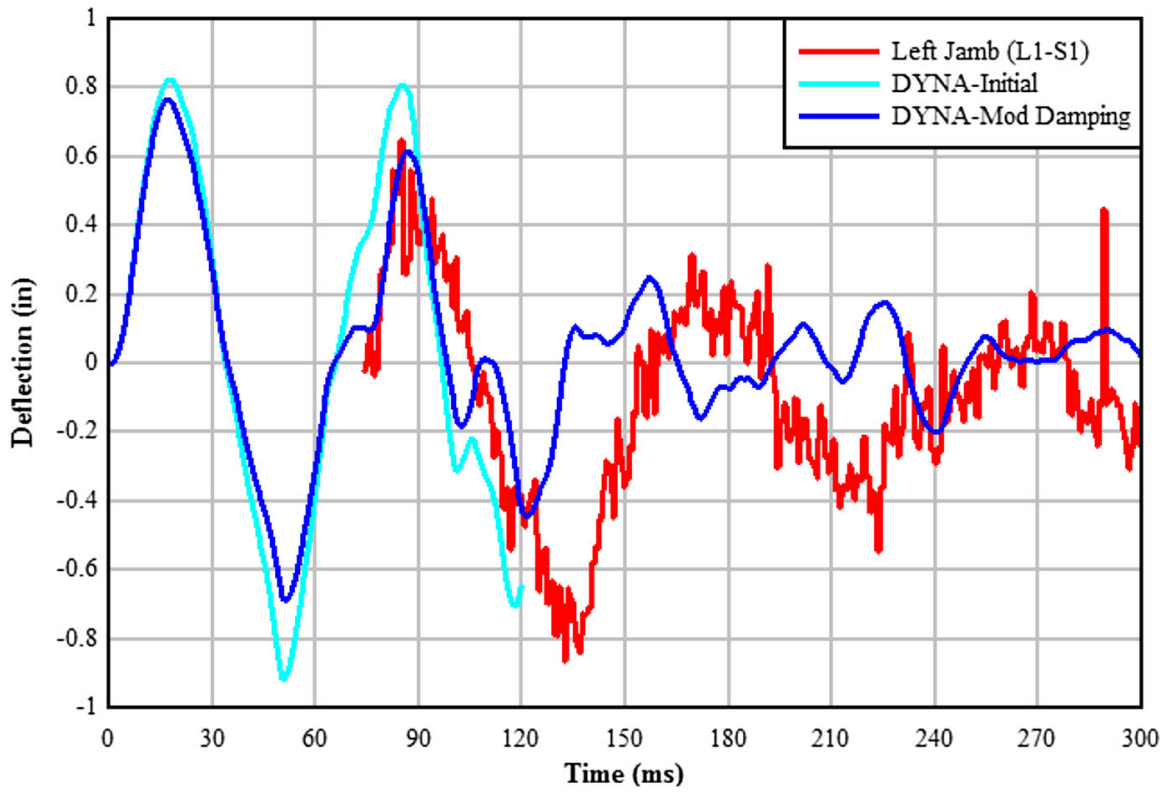


Fig. 32 FEA Mullion response comparisonTest 1 , laser gauge 2
Fig. 33 FEA mullion response comparisonTest 3, laser gauge 1
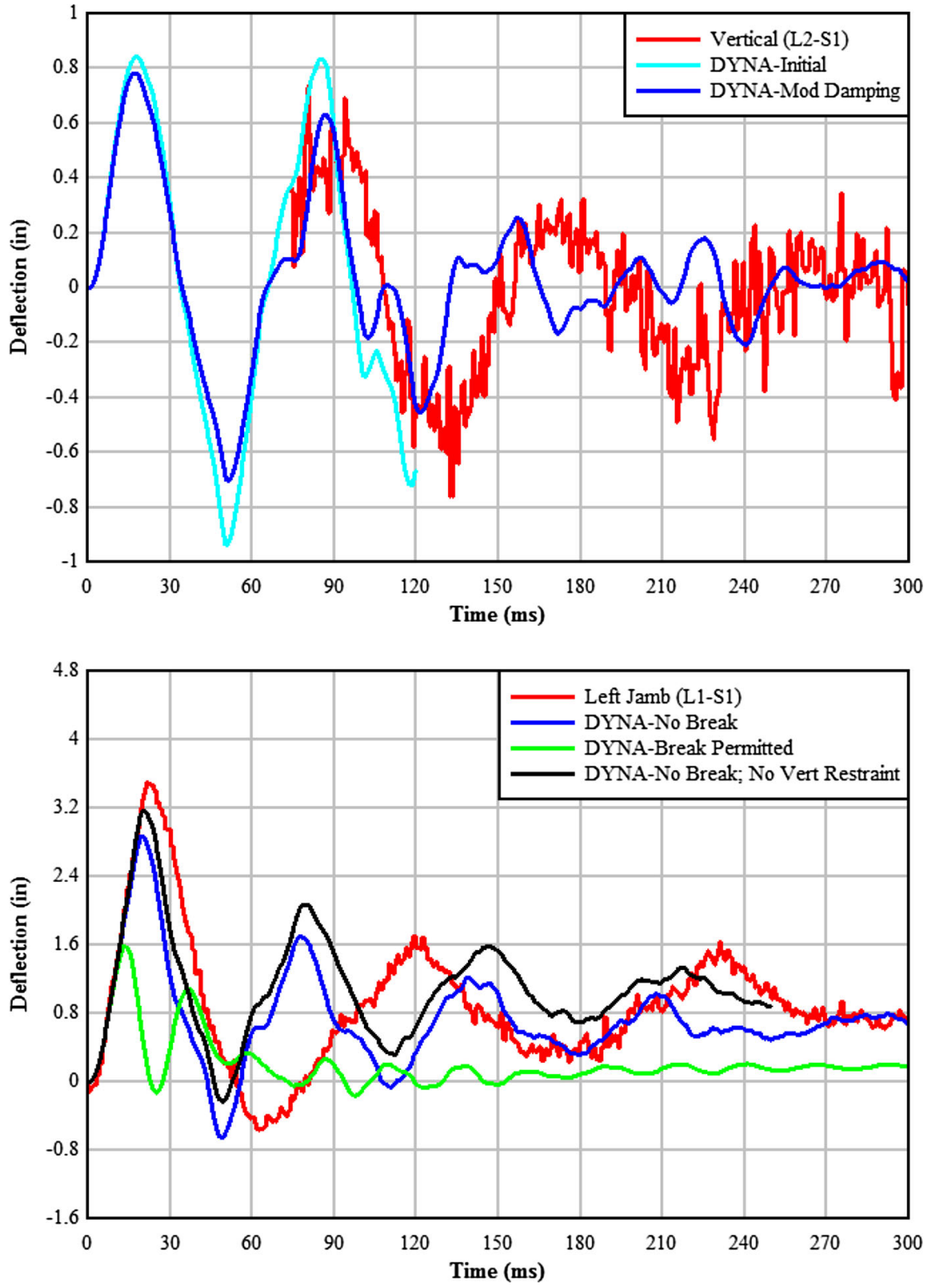

the measured data essentially begins at the mullions' second inbound incursion. Two computational predictions are shown in both figures. The light blue curves represent the predicted displacement histories when no structural damping is considered in computational space, and the dark blue curves represent the predicted displacement histories when $7 \%$ structural damping is considered.

A comparison of the Test 3 left jamb and vertical mullion laser gauge displacement histories with those predicted in LS-DYNA is shown in Figs. 33 and 34 , respectively. Three computational predictions are shown in both figures. The dark blue curves represent the predicted displacement histories when no glass-break is permitted. The black curves represent the predicted displacement histories when no glassbreak is permitted and no vertical restraint is provided at the specimen support locations, and the green curve represents the predicted displacement histories when the GFPM glass-break methodology is permitted. Dur- 
Fig. 34 FEA mullion response comparisonTest 3 , laser gauge 2
Fig. 35 FEA mullion response comparisonTest 5, laser gauge 1
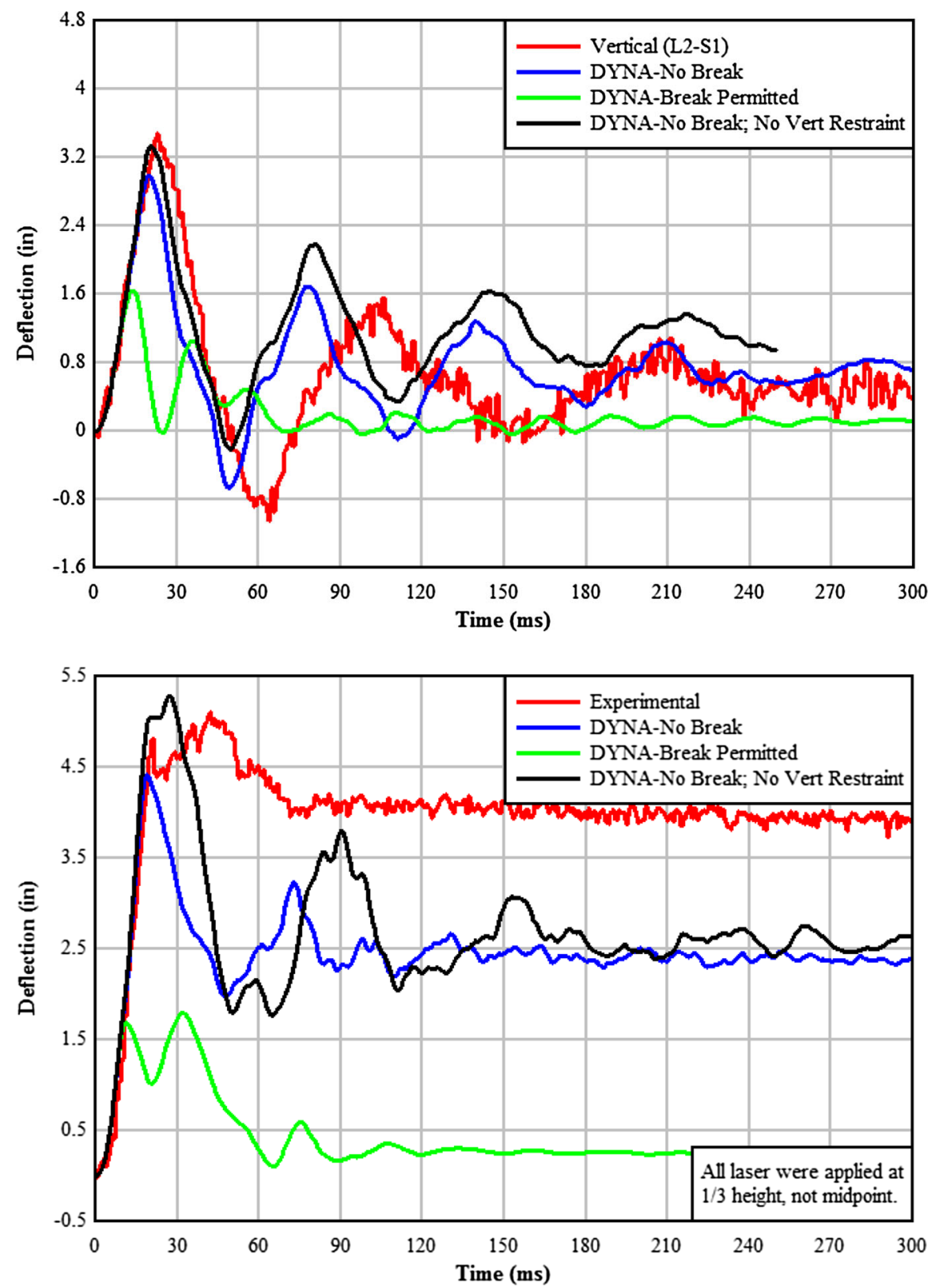

ing the break-permitted simulation, early-time glazing failure occurred before the end of the blast load duration. Consequently, the effective load transferred to the mullions was reduced relative to what actually occurred during the test, where the upper IGUs failed but only the threat-side (outer) lite of one of the lower IGUs cracked. The result of this simulation was a grossly under-predicted peak inbound response relative to the no-break simulations and a poor overall prediction of mullion response. The predicted mullion response for the no-break simulations yielded much better results. The no-break simulation that allowed for vertical movement at the specimen support locations produced slightly better mullion response predictions, which suggests minor flexing of the support connections during the test. Again, later time response was not predicted as well, but such is deemed of secondary importance for a design-level analysis.

A comparison of the Test 5 left jamb and vertical mullion laser gauge displacement histories with 
Fig. 36 FEA mullion response comparisonTest 5 , laser gauge 2

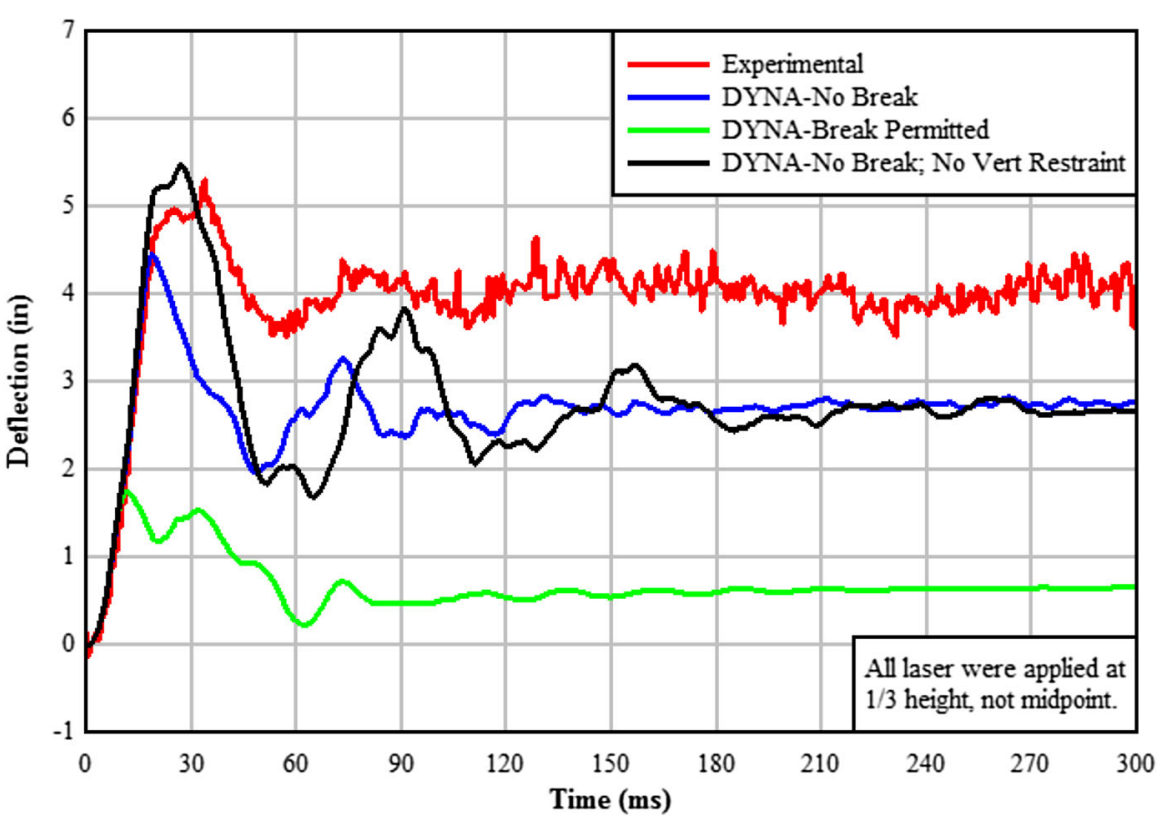

those predicted in LS-DYNA is shown in Figs. 35 and 36, respectively. Three computational predictions are shown in both figures. The dark blue curves represent the predicted displacement histories when no glassbreak is permitted. The black curves represent the predicted displacement histories when no glass-break is permitted and no vertical restraint is provided at the specimen support locations, and the green curve represents the predicted displacement histories when the GFPM glass-break methodology is permitted. During the break-permitted simulation, early-time glazing failure occurred before the end of the blast load duration. Consequently, the effective load transferred to the mullions was reduced relative to what actually occurred during the test. The result of this simulation was a grossly under-predicted peak inbound response relative to the no-break simulations and a poor overall prediction of mullion response. Mullion response predictions from the no-break simulation were better than those from the break-simulation, but peak response was still under-predicted by approximately $10 \%$. The nobreak and no vertical restraint simulation produced the best peak mullion response predictions, therefore again suggesting that flexing of the specimen support connections likely occurred during the test. High-speed video of the specimen's top support connection further confirms that flexing of the connection did indeed occur during the test. It can also be noted that both no- break simulations provided poor predictions of residual mullion/jamb displacement. Post-test observations revealed significant local damage (e.g., unzipping of vertical mullion interlocks and local web buckling) to both jambs and the vertical mullion. This type of local damage is believed to have contributed to additional residual displacement above and beyond what would be expected from pure section yielding and flexural hinge development. Furthermore, the equivalent beam elements employed in the design-level finite element model are not capable of capturing such local damage, and therefore would be expected to under-predict residual mullion displacement in this case.

\section{Conclusions}

Glazing, mullion, and connection load data collected during the five shock tube tests on full-scale curtain walls support the further development of WhAM (a fast-running design and analysis tool for curtain walls subjected to blast and other dynamic service loads). The shock tube tests provided a range of response data from elastic system response (Test 1) to plastic system response with significant deformations (Test 5). During Test 1, all mullions and glazing responded elastically without any permanent deformation. During Test 2 , one lite in three of the four IGUs failed and elastic 
mullion response was noted. The Test 2 load was on the cusp of failure of the upper IGUs. During Test 3, the upper IGUs failed and one lite in one lower IGU cracked, the main response being further elastic mullion response. During Test 4, the upper IGUs failed and the lower IGUs exhibited significant response through PVB stretching. During Test 4, the vertical mullions and jambs yielded with permanent deformation noted. During Test 5, the glazing and vertical mullions/jambs were pushed even further to near failure of the PVB interlayer (two sides of one lower IGU experienced significant pull out failure).

Upon review of the first 20-ms of DIC glazing data for all tests, it was concluded that the no-break finite element simulations yielded reasonably good glazing performance predictions. Early-time multi-modal behavior (i.e., non-sinusoidal deformation shape) of the glass was captured, and peak glazing response was predicted fairly well when no glass failure occurred. These conclusions suggest that the current computational modeling strategy for IGU units, including glass lites, air gaps, and structural silicone, is well defined. Moderate early-time latency of measured glazing response was observed relative to the design-level finite element predictions. While this observation can certainly be further investigated, it is currently hypothesized that the observed early-time latency may be attributed to inertial effects associated with acceleration of the entire shock tube apparatus (shock tube movement confirmed by string pot measurements during the tests). During post-processing of the measured data, shock tube displacement was removed from all laser and DIC data. However, effects associated with acceleration of the entire shock tube apparatus were not explicitly accounted for during the design-level finite element simulations.

It was also concluded that the simplified modeling strategy for aluminum mullions is a viable and computationally efficient approach for WhAM. The mullion modeling assumptions include a Timoshenkotype beam element formulation, an equivalent rectangular tube cross-section, nonlinear constitutive model, and Cowper-Symonds approach to capturing strainrate effects. Comparison of all no-break simulation results with mullion laser gauge data demonstrates the ability of the current mullion modeling strategy to accurately predict peak mullion response. In addition, for Test 3 and Test 4, residual mullion displacements were also accurately predicted. Test 5 residual mullion displacements were slightly under-predicted, and it is believed that the under-prediction was due to local damage (unzipping of vertical mullion section and local buckling) that could not be computationally captured with the simplified beam element representation of the jambs and vertical mullion. That said, such post-peak response is of secondary importance for a design-level tool such as WhAM.

An improved finite element implementation of the Glass Failure Prediction Model will significantly improve glass-break predictions. Accordingly, improved glass-break predictions will significantly improve predictions of overall system (glazing and mullion) response, as illustrated by the difference in prediction accuracy between the no-break and breakpermitted finite element analysis results presented herein.

Shock tube test data will be used to re-cast the current WhAM glass-break methodology such that the core GFPM theory be utilized to directly interrogate the stress field of a glass lite to determine whether a probabilistically based "critical" stress value has been reached or exceeded on a time step basis during an explicit dynamic analysis. This proposed approach for incorporating the GFPM into a finite element framework is directly aligned with the state-of-the-art procedure currently being finalized by the ASTM E1300 committee. The DIC data will be extremely valuable in validating this proposed glass-break model. Furthermore, such a model would reside on the material level and thus would be easily extended to more exotic façade systems and components such as triplepane IGUs, curved glass, and point-supported glass. This effort is currently under way and will ultimately result in an LS-DYNA user-defined material model (UMAT).

Shock tube test data will also be used to validate a UMAT for PVB material, which is currently being developed. The PVB UMAT will be based on hyperelastic constitutive behavior and enhanced to include (a) strain-based stiffening due to the post-break presence of adhered pieces of glass and (b) stiffening due to strain-rate effects.

Acknowledgements PEC acknowledges the significant support provided by ABS Consultants for shock tube testing and Enclos for overall project funding, guidance and curtain wall materials for testing 


\section{References}

Alberson, R.M., Davis, C.E., Marchand, K.A.: High Strength Glass Testing and Model Validation for Static and Dynamic Loading. In: Proceedings Structures Congress 2013: Bridging Your Passion with Your Profession, pp. 203-215. ASCE, Reston (2013). doi:10.1061/9780784412848

ASTM Standard: ASTM E1300 Standard Practice for Determining Load Resistance of Glass in Buildings. ASTM International, West Conshohocken (2012). doi:10.1520/F2248-09

Beason, W.L., Morgan, J.R.: Glass failure prediction model. J. Struct. Eng. 110(2), 197-212 (1984)

Bedon, C., Amadio, C.: Exploratory numerical analysis of two-way straight cable-net façades subjected to air blast loads. Eng. Struct. 79(11), 276-289 (2014). doi:10.1016/j. engstruct.2014.08.023

Cowper, G.R., Symonds, P.S.: Strain Hardening and Strain Rate Effects in the Impact Loading of Cantilever Beams, Applied Mathematics Report. Brown University, Providence (1958)

Davis, C.E., Marchand, K.A., Conrath, E.J.: Clear Polymer Coated Windows for ATFP Applications: Quasi-static and Dynamic Testing and Analysis. Test and Analysis Report Prepared for PPG Industries, Allison Park (2009)

Deng, R., Jin, X.: Numerical simulation for blast analysis of insulating glass in a curtain wall. Int. J. Comput. Methods Eng. Sci. Mech. 11(3), 162-171 (2010). doi:10.1080/ 15502281003702302

Dow Corning: Dow Corning 995 Silicone Structural Glazing Sealant. Product Information Sheet, Reference No. 621260E-01, Stuttgart (2009)

Hidallana-Gamage, H.D., Thambiratnam, D.P., Perera, N.J.: Failure analysis of laminated glass panels subjected to blast loads. Eng. Fail. Anal. 36, 14-29 (2014). doi:10.1016/j. engfailanal.2013.09.018
Larcher, M., Solomos, G., Casadei, F., Gebbeken, N.: Experimental and numerical investigations of laminated glass subjected to blast loading. Int. J. Impact Eng. 39, 42-50 (2012). doi:10.1016/j.ijimpeng.2011.09.006

Livermore Software Technology Corporation.: LS-DYNA Keyword User's Manual, Vol. I \& II. Software User's Manuals; Livermore. http://www.lstc.com/download/manuals (2015)

MPA Stuttgart: Mechanical Tests on Structural Silicone Joints at Higher Load Velocities up to $5 \mathrm{~m} / \mathrm{s}$. Test Report prepared for Dow Corning GmbH, Stuttgart (2007)

Pelfrene, J., Kuntsche, J., Van Dam, S., Van Paepegem, W., Schneider, J.: Critical assessment of the post-breakage performance of blast loaded laminated glazing experiments and simulations. Int. J. Impact Eng. 88, 61-71 (2016). doi:10. 1016/j.ijimpeng.2015.09.008

Schneider, J., Kolling, S., Kuntsche, J., Moennich, S.: Tensile properties of different polymer interlayers under high strain rates. In: Engineered Transparency-International Conference at Glasstec Proceedings, Dusseldorf (2012)

Thomson, T.W., Dahleh, D.M.: Theory of Vibration with Applications, 5th edn. Pearson, Upper Saddle River (1997)

US Army Corps of Engineers Protective Design Center: Single Degree of Freedom Blast Effects Design Spreadsheet for Windows Version 1.0 (SBEDS-W). US Army Corps of Engineers Protective Design Center, Omaha (2014)

Vallabhan, C.V.G., Wang, B.Y.-T.: Nonlinear Analysis of Rectangular Glass Plates by Finite Difference Method. Institute for Disaster Research, Texas Tech University, Lubbock (1981)

Zhang, X., Hao, H., Ma, G.: Parametric study of laminated glass window response to blast loads. Eng. Struct. 56, 1707-1717 (2013). doi:10.1016/j.engstruct.2013.08.007 